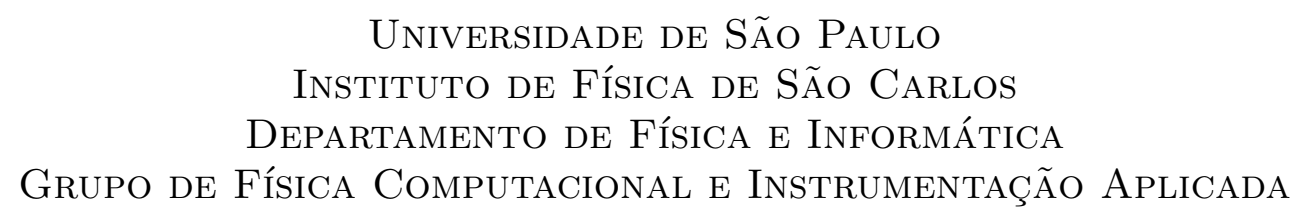

Paulo Matias

Novo método para assinatura e identificação de sinais de eletrocomunicação de peixes elétricos de campo fraco da espécie Gymnotus carapo

São Carlos, SP 

Paulo Matias

\section{Novo método para assinatura e identificação de sinais de eletrocomunicação de peixes elétricos de campo fraco da espécie Gymnotus carapo}

Dissertação apresentada ao Programa de PósGraduação em Física do Instituto de Física de São Carlos da Universidade de São Paulo, para obtenção do título de Mestre em Ciências.

Área de concentração: Física Aplicada Opção: Física Computacional

Orientador: Prof. Dr. Jan Frans Willem Slaets

Versão original

São Carlos, SP 


\begin{abstract}
AUTORIZO A REPRODUÇÃO E DIVULGAÇÃO TOTAL OU PARCIAL DESTE TRABALHO, POR QUALQUER MEIO CONVENCIONAL OU ELETRÔNICO, PARA FINS DE ESTUDO E PESQUISA, DESDE QUE CITADA A FONTE.
\end{abstract}

Ficha catalográfica elaborada pelo Serviço de Biblioteca e Informação IFSC/USP

\title{
Matias, Paulo.
}

Novel method for signature and identication of electrocommunication signals of the weakly electric fish Gymnotus carapo / Paulo Matias; orientador Jan Frans Willem Slaets.-- São Carlos, 2011.

$51 \mathrm{p}$.

Dissertação (Mestrado em Ciências - Área de concentração: Física Aplicada - Opção Física Computacional) - Instituto de Física de São Carlos da Universidade de São Paulo.

1. Eletrosiologia. 2. Eletrocomunicação. 3.Processamento de sinais. 4. Aprendizagem de máquina. 5. Instrumentação científica. I. Título. 


\section{FOLHA DE APROVAÇÃO}

Paulo Matias

Dissertação apresentada ao Instituto de Física de São Carlos da Universidade de São Paulo para obtenção do título de Mestre em Ciências.

Área de Concentração: Fisica Aplicada Opção: Física Computacional

Aprovado(a) em: 22.02.2011

\section{Comissão Julgadora}

Prof(a). Dr(a). Angel Ariel Caputi Cavalli Instituição: IIBCE

Assinatura

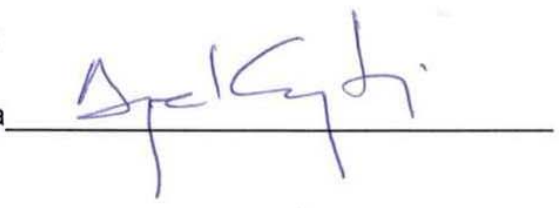

Prof(a). Dr(a). Antonio Carlos Roque da Silva_Fitho
Instituição: FFCLRP/USP Assinatura Prof(a). Dr(a). Jan Frans Willem Sląts
Instituição: IFSC/USP 



\section{AGRADECIMENTOS}

Ao meu orientador, Jan Frans Willem Slaets, pela paciência e por estar sempre pronto a atender e auxiliar, com grande dedicação.

Ao Reynaldo Daniel Pinto e à Caroline Garcia Forlim, pelo auxílio nos experimentos e pelas discussões de grande valor a respeito dos peixes elétricos.

Ao Lirio Onofre Baptista de Almeida pelas incontáveis discussões sobre eletrônica e instrumentação científica.

Aos professores pertencentes ao grupo que sempre acrescentam seus comentários a respeito de nossos trabalhos, Roland Köberle e Leonardo Maia.

Ao Leonardo Silva Amaral e ao Rodrigo Capobianco Guido por fornecerem gentilmente o acesso a um computador com processador Intel Core 2 Quad.

Ao Rafael Giordano Viegas pelo inestimável auxílio na formatação durante a fase final desta dissertação.

A todos os demais que integram o grupo, ou que o integraram recentemente, Ailton Batista Alves, Bóris Marin, Carolina Menezes Silvério, Gisele Strieder Phillipsen, Ingrid Esteves, Ivanilda Helena Zucolotto de Stefani, Jessica dos Santos, Lucas Eduardo Visolli Sala, Ludmila Brocchini Rodrigues, Mario Gazziro, Nataly Horner, Nelson Fernandes e Rafael Tuma Guariento.

Aos meus familiares, em especial a meus pais, meus irmãos e à minha avó, e à minha amada Mesailde.

À CAPES pelo suporte financeiro durante a essa pesquisa. 



\section{RESUMO}

MATIAS, P. Novo método para assinatura e identificação de sinais de eletrocomunicação de peixes elétricos de campo fraco da espécie Gymnotus carapo. 2011. 51p. Dissertação (Mestrado) - Instituto de Física de São Carlos - Universidade de São Paulo, São Carlos, 2011.

Desenvolvemos um método capaz de reconhecer assinaturas de descargas do órgão elétrico de peixes de campo elétrico fraco da espécie Gymnotus carapo. A assinatura de um peixe é computada com base no espectro de frequências de suas descargas, extraído por meio de uma transformada de Fourier, ou com base em uma análise tempo-frequência das mesmas, realizada por meio de uma transformada complexa de dupla árvore de pacote wavelet. Com o auxílio de uma máquina de vetores de suporte, um método de classificação supervisionada, utilizamos essas assinaturas para identificar, com boa precisão (estimada em 96\%), o peixe de origem de cada descarga de órgão elétrico recebida durante uma aquisição com dois peixes movimentando-se livremente em um mesmo aquário.

Palavras-chave: Eletrofisiologia. Eletrocomunicação. Processamento de sinais. Aprendizagem de máquina. Instrumentação científica. 



\section{$A B S T R A C T$}

MATIAS, P. Novel method for signature and identification of electrocommunication signals of the weakly electric fish Gymnotus carapo. 2011. 51p. Dissertação (Mestrado) - Instituto de Física de São Carlos - Universidade de São Paulo, São Carlos, 2011.

We developed a method capable of recognizing signatures of the electric organ discharges of the weakly electric fish Gymnotus carapo. The signature of a fish is computed based on the frequency spectrum of its discharges, extracted using a Fourier transform, or based on a time-frequency analysis, done using a dual-tree complex wavelet packet transform. With the aid of a support vector machine, a supervisioned classification method, we use these signatures to identify, with good precision (estimated at 96\%), the source fish of each electric organ discharge received during an acquisition with two fish freely swimming in the same aquarium.

Keywords: Electrofisiology. Electrocommunication. Signal processing. Machine learning. Scientific instrumentation. 



\section{LISTA DE FIGURAS}

Peixe elétrico da espécie Gymnotus carapo . . . . . . . . . . . . . 19

Diagrama esquematizado do aquário utilizado para aquisição . . . 20

Forma de onda típica de descargas de um mesmo peixe . . . . . . 20

Comparação da resposta em frequência entre janelas retangular e de Hamming . . . . . . . . . . . . . . . . . . . . . . . . . . . 23

Comparação entre assinaturas do peixe utilizando janelas retangular e de Hamming . . . . . . . . . . . . . . . . . . . . . . . . . . 24

Forma típica das assinaturas computadas utilizando a transformada de Fourier . . . . . . . . . . . . . . . . . . . . . 24

Transformada de pacote wavelet em um sinal com diferença de fase variável entre componentes de frequência . . . . . . . . . . . . 26

10 Transformada complexa de dupla árvore de pacote wavelet em um sinal com diferença de fase variável entre componentes de frequência 27 Histogramas de amostras de níveis diferentes de uma DT-CWPT . 
Exemplo de pontos linearmente inseparáveis sendo utilizados para treinar uma SVM . . . . . . . . . . . . . . . . 33

17 Resistência dos métodos a ruído branco aditivo gaussiano . . . . . 40

18 Resistência dos métodos a sobreposição com descarga de outro peixe 41

19 Resistência dos métodos a sobreposição com descarga deslocada de outro peixe . . . . . . . . . . . . . . . . . . . . . 41

20 Intervalos entre descargas em experimento com estímulo e peixe real, usando assinatura DT-CWPT . . . . . . . . . . . . 43

21 Intervalos entre descargas em experimento com estímulo e peixe real, usando assinatura FFT . . . . . . . . . . . . . . . 43

22 Resistência a sobreposição com descarga deslocada no modelo do peixe e do estímulo . . . . . . . . . . . . . . . . . . . 44

23 Intervalos entre descargas em experimento com dois peixes, usando assinatura FFT . . . . . . . . . . . . . . . . 45

24 Intervalos entre descargas em experimento com dois peixes, usando assinatura DT-CWPT . . . . . . . . . . . . . 45 


\section{SUMÁRIO}

1 Introdução

2 Metodologia

2.1 Aquisição de descargas do órgão elétrico . . . . . . . . . . . . . . . . . . . 19

2.2 Determinação da assinatura de um peixe . . . . . . . . . . . . . . 22

2.2.1 Transformada discreta de Fourier . . . . . . . . . . . . . . 22

2.2.2 Transformada complexa de dupla árvore de pacote wavelet . . . . . 25

2.2.3 Comparação visual entre os dois métodos de assinatura . . . . . . . 30

2.3 Máquina de vetores de suporte . . . . . . . . . . . . . . . . 32

\section{Desenvolvimento}

3.1 Aspectos gerais de implementação . . . . . . . . . . . . . . . . . . 35

3.2 Implementação do programa de treino . . . . . . . . . . . . . . 36

3.3 Implementação do programa de reconhecimento . . . . . . . . . . . . . . 38

4 Resultados

4.1 Validação cruzada e reconhecimento de um peixe sozinho . . . . . . . . . . 39

4.2 Avaliação da resistência a ruídos . . . . . . . . . . . . . . . . . . 40

4.3 Estimativa do erro real do método . . . . . . . . . . . . . . . . . . . . 42

4.4 Experimentos preliminares com dois peixes . . . . . . . . . . . 44 
REFERÊNCIAS 


\section{Introdução}

O sistema nervoso é um dos sistemas biológicos mais fascinantes e complexos da natureza, composto por uma grande quantidade de elementos não-lineares que interagem entre si, dispostos em uma complicada hieraquia de conexões, através da qual fluem informações codificadas de forma ainda pouco compreendida. Um grande esforço tem sido depreendido pela comunidade científica na empreitada de entender e decifrar o funcionamento desses sistemas em diversas escalas, desde neurônios individuais até sistemas extremamente intrincados como o cérebro humano.

O objeto deste trabalho é um sistema bastante interessante para o estudo de como os sistemas nervosos se comportam em um nível mais alto, propiciando experimentos que envolvem tanto aspectos de codificação neural quanto aspectos comportamentais dos animais. Trata-se do sistema de eletrocomunicação de peixes elétricos de campo fraco, em especial dos peixes da espécie Gymnotus carapo. O sinal elétrico desses peixes é de fácil deteção. Eles são uns dos poucos animais nos quais é possível realizar, de maneira simples e não invasiva, a medida de um sinal produzido por um subsistema interno complexo e especializado.

Peixes elétricos podem ser classificados como onduladores ou pulsadores (1). Os onduladores emitem descargas a uma frequência constante, de forma a produzir um campo elétrico praticamente contínuo e similar a uma onda senoidal (2). Já os pulsadores, classe à qual pertence o Gymnotus carapo, produzem descargas rápidas separadas por intervalos variáveis de tempo (3), apresentando assim um sinal com formato similar ao emitido por neurônios pulsantes (spiking neurons).

Essas descargas são produzidas por um órgão especializado, denominado órgão elétrico (OE), sendo portanto chamadas de descargas do órgão elétrico (DOE), também referidas pelo termo inglês electric organ discharges (EOD). Nos peixes da espécie Gymnotus carapo, o órgão elétrico é formado por um conjunto de células musculares denominadas eletrócitos, 
que estão, geralmente, entre as maiores células do animal, apresentando-se na forma de disco, fita ou fuso (1).

O órgão elétrico serve basicamente a dois propósitos: eletrolocalização e eletrocomunicação. A eletrolocalização é possível pois objetos que estejam ao alcance do campo elétrico produzido pelo peixe alteram a corrente induzida em seus eletrócitos. Desta forma, o peixe obtém uma imagem elétrica de seus arredores (4), permitindo que o mesmo se oriente mesmo em condições de baixa iluminação. Os eletrócitos são encontrados ao longo de toda a epiderme do peixe, porém estão mais concentrados em uma pequena região em torno da mandíbula, denominada "fóvea elétrica" (5). O mecanismo de eletrolocalização permanece ativo mesmo durante o sono do peixe (6), provavelmente com a finalidade de perceber tentativas de ataque surpresa de predadores, o que demonstra a importância desse mecanismo para o animal.

A eletrocomunicação é importante para a interação social entre os peixes. O estado comportamental de um peixe frequentemente interfere em sua atividade elétrica. A relação de dominância entre peixes também parece ser fortemente sinalizada por meio da eletrocomunicação (1).

Todavia, na maioria dos trabalhos atualmente encontrados na literatura em que se estuda a resposta do peixe a estímulos elétricos, restringe-se drasticamente os movimentos do animal (7), e utiliza-se apenas um protocolo de estímulo unidirecional, no qual séries de dados são reproduzidas na forma de sinais elétricos predefinidos para o peixe, sem que este exerça qualquer influência sobre os estímulos. Apesar de tais métodos serem extremamente úteis para a execução de experimentos relacionados à eletrolocalização, é bastante desejável a elaboração de novos métodos experimentais que possibilitem a livre movimentação dos peixes e a observação da comunicação bidirecional entre dois animais.

Recentemente, foram realizados experimentos com dois peixes nadando livremente em aquários separados, conectados por meio de um dispositivo eletrônico intermediário, capaz de registrar o aquário de origem de cada pulso e de retransmiti-lo ao outro aquário (8). Entretanto, esse tipo de experimento poderia ser tornado mais naturalístico caso fosse 
possível situar os peixes em um mesmo aquário.

Observa-se que diferentes peixes aparentam possuir formas de onda ligeiramente diferentes em suas descargas de órgão elétrico, tendo sido especulado que essas diferenças possam ser utilizadas para reconhecimento pelos próprios peixes (9). Já havia sido sugerido um método para a identificação do peixe de origem de uma descarga por meio da observação de sua forma de onda no domínio do tempo (10), porém verificou-se, na mesma publicação referida, que tal forma de onda não é exatamente constante quando o peixe muda de posição com relação ao dipolo usado para aquisição. Ressaltou-se que a espécie Gymnotus carapo, em especial, apresenta grande variação dessa forma de onda em função da posição do peixe.

Este trabalho propõe portanto um novo método, que calcula uma assinatura aproximadamente fixa das descargas de órgão elétrico de um certo peixe, independente de sua posição. Foram elaboradas duas variações deste método. A primeira variação utiliza para o cálculo da assinatura simplesmente as componentes de frequência das descargas, descartando completamente informações de fase de cada componente. A segunda variação utiliza uma representação intermediária no plano tempo-frequência, calculada por meio de uma transformada complexa de dupla árvore de pacote wavelet (11-12). A melhor base (best basis) para representação é escolhida por meio de um algoritmo proposto no presente trabalho, de forma a maximizar a distinguibilidade entre diferentes classes de sinais, no caso, entre diferentes peixes de origem.

Um conjunto de assinaturas computadas a partir de diversas descargas cujos peixes de origem são conhecidos é utilizado para treinar uma máquina de vetores de suporte (13-14), um método de classificação supervisionada. Uma vez treinado, o método é capaz de identificar, com bastante precisão, o peixe de origem de uma descarga para a qual este não é previamente conhecido.

O método proposto é implementado em linguagem C, de forma a obter um nível razoável de performance e a facilitar futuras implementações de identificação e processamento com sistemas operacionais de tempo real. A implementação final é avaliada por meio de 
alguns experimentos, e sua eficácia, limitações atuais e novas direções para a pesquisa são discutidas. 


\section{Metodologia}

\subsection{Aquisição de descargas do órgão elétrico}

Peixes elétricos da espécie Gymnotus carapo (Figura 1) são colocados em um aquário de vidro de $40 \times 40 \times 44 \mathrm{~cm}$, disposto em uma caixa com gaiola de Faraday dupla e isolamento acústico e mecânico. Detalhes sobre a montagem do aquário são descritos em (8).

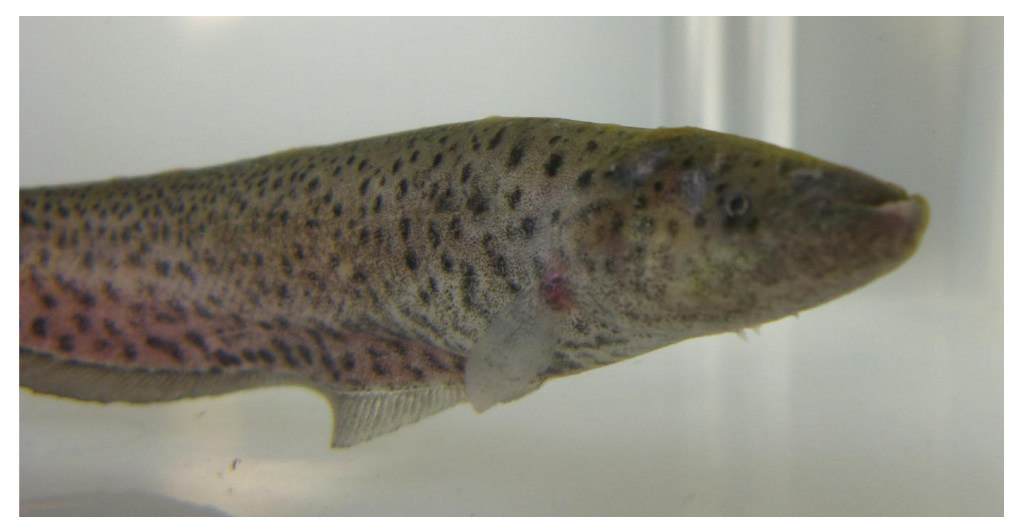

Figura 1 - Peixe elétrico da espécie Gymnotus carapo.

Como na Figura 2, o aquário possui oito eletrodos localizados em seus vértices. Um dentre esses eletrodos é escolhido como referência, em relação à qual os sinais dos outros sete eletrodos são amplificados diferencialmente.

Cada um dos sete sinais amplificados é conectado a uma placa de aquisição PCI-MIO16E-1, da National Instruments. Essa placa possui resolução de 12 bits, e opera na faixa de -10 a 10 volts. Os sinais obtidos durante os experimentos relacionados a este trabalho foram capturados utilizando o software Dasylab (Dasytech, Alemanha). Entretanto, nosso software de análise de sinais foi desenvolvido de forma a tornar bastante simples sua adaptação para capturar dados diretamente de drivers do Comedi, em ambiente Linux.

Todos os dados foram gravados à taxa de amostragem de $50 \mathrm{kHz}$, taxa máxima à qual 


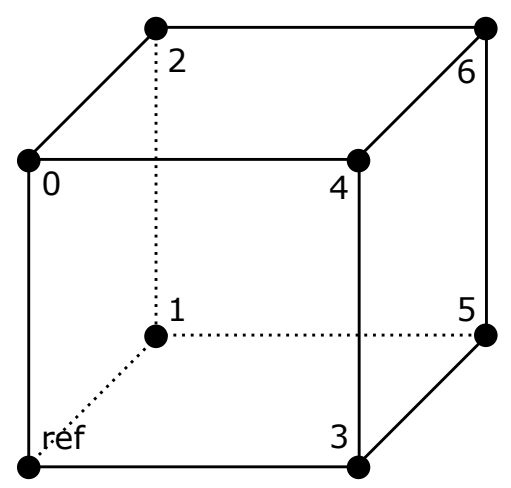

Figura 2 - Diagrama esquematizado do aquário utilizado para aquisição. A disposição em oito eletrodos permite a aquisição de sinais de sete canais ( 0 a 6 ), amplificados a partir do eletrodo de referência (ref).

nosso conjunto de aquisição suportou gravar os dados em disco sem esvaziar o buffer.

Em uma primeira etapa, são realizadas aquisições de cada peixe sozinho por vez no aquário. Os dados obtidos são utilizados para computar as assinaturas e treinar os modelos de reconhecimento. A disponibilidade de sete canais diferentes de aquisição é bastante oportuna nesta fase, pois é possível capturar descargas a partir de uma grande variedade de posições relativas entre peixe e eletrodos, o que tende a melhorar a qualidade do modelo treinado utilizando esses dados.
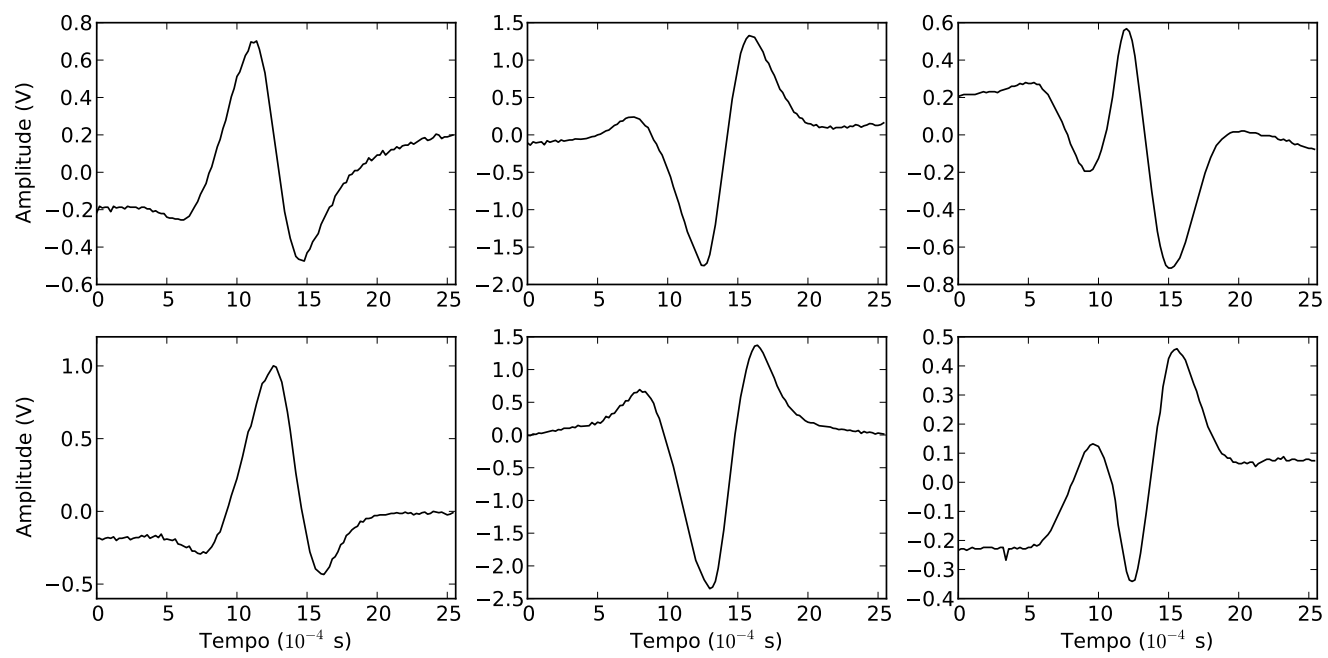

Figura 3 - Forma de onda típica de descargas de um mesmo peixe. No domínio do tempo, o formato das descargas é bastante variável.

A Figura 3 mostra o formato típico das descargas de órgão elétrico de um mesmo peixe 
durante essa primeira etapa de uma aquisição. A figura evidencia como esse formato é bastante variável no domínio do tempo.

A segunda etapa de uma aquisição é realizada com dois peixes situados no mesmo aquário. Os dados obtidos alimentam o modelo, cujo objetivo é reconhecer o peixe de origem de cada uma das descargas. Nesta etapa, a disponibilidade de sete canais também é conveniente pois facilita a separação das descargas quando estas ocorrem exatamente no mesmo instante, ou em instantes muito próximos.

Como mostra a Figura 4, caso apenas os canais de números 3 ou 5, que possuem sinal de maior amplitude, fossem utilizados para o reconhecimento, a existência de duas descargas naquele instante não seria detetada pelo método, pois nestes canais a descarga de um peixe é encoberta pela descarga de outro, que está muito mais próximo dos eletrodos correspondentes.

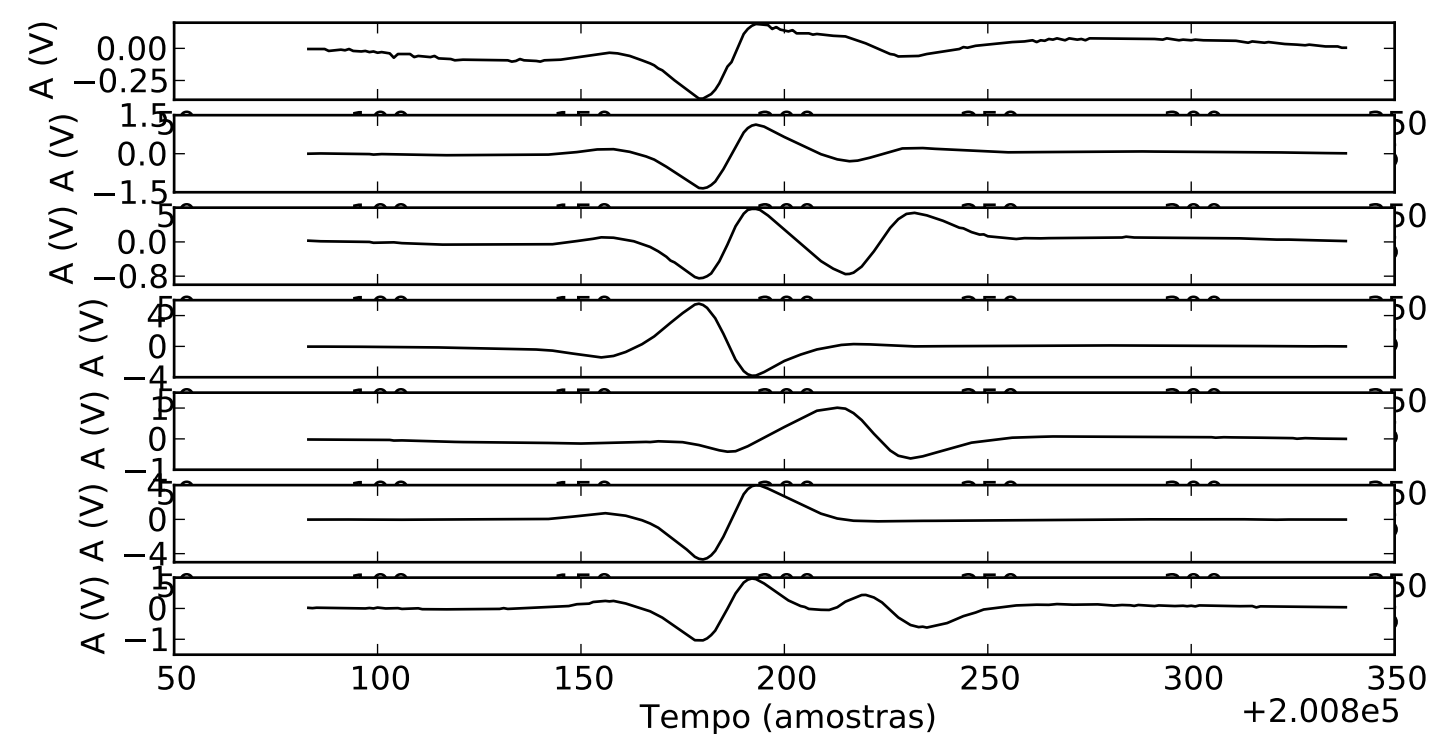

Figura 4 - Visualização de uma descarga simultânea em diversos canais. Sinais dos eletrodos de 0 a 6 são dispostos de cima para baixo. Nota-se que um dos peixes estava bastante próximo aos eletrodos de números 3 e 5 durante a descarga, encobrindo, nestes canais, o sinal do outro peixe. 


\subsection{Determinação da assinatura de um peixe}

\subsubsection{Transformada discreta de Fourier}

A transformada discreta de Fourier $X_{k}$ de um sinal temporal $x_{n}$ é dada por:

$$
X_{k}=\sum_{n=0}^{N-1} x_{n} e^{-\frac{2 \pi i}{N} k n} \quad k=0, \ldots, N-1
$$

A primeira variação do método utiliza a transformada $X_{k}$ de uma janela de 128 amostras em torno da descarga, calculada por meio de uma transformada rápida de Fourier (Fast Fourier Transform, ou FFT).

É tomado o módulo do sinal transformado para descartar toda a informação de fase presente no mesmo. Isso é feito pois há um alto grau de variação da fase nas componentes de frequência das descargas do peixe quando este muda de posição. O sinal final é, então, normalizado de acordo com sua maior amplitude, dando origem à assinatura $S_{k}$ :

$$
S_{k}=\frac{\left|X_{k}\right|}{\max \left|X_{k}\right|} \quad k=1, \ldots, \frac{N}{2}
$$

O índice $k$ é tomado no intervalo acima pois a componente DC do sinal é descartada, de forma que tomamos $k \geq 1$, e pois, por $x_{n}$ se tratar de um sinal real, os valores de $X_{k}$ com $k>\frac{N}{2}$ serão iguais ao conjugado complexo dos valores anteriores.

Um detalhe prático importante para o cálculo da transformada discreta de Fourier é que o uso de janelas retangulares, ou seja, a simples extração de um conjunto de amostras do sinal original para o cálculo de sua transformada, não costuma funcionar bem. Isso se deve ao fato que essa operação é equivalente a multiplicar o sinal original por uma função retangular, cuja transformada contínua de Fourier é uma função do tipo $\sin (\pi k) / k$. Como, pelo teorema da convolução, multiplicação amostra-a-amostra no domínio do tempo é equivalente a convolução no domínio da frequência, todas as frequências presentes no sinal original serão espalhadas ao longo das componentes de Fourier de acordo com essa função. Apenas frequências $k$ que fossem exatamente iguais aos valores dos bins $k^{\prime}$ da 
transformada discreta não seriam espalhadas, pois $\sin \left[\pi\left(k-k^{\prime}\right)\right]$ se anularia para todos esses bins devido a $k-k^{\prime}$ ser inteiro.

Portanto, utilizamos a janela de Hamming para extrair do sinal original as 128 amostras a serem transformadas:

$$
w(n)=0.54-0.46 \cos \left(\frac{2 \pi n}{N-1}\right)
$$

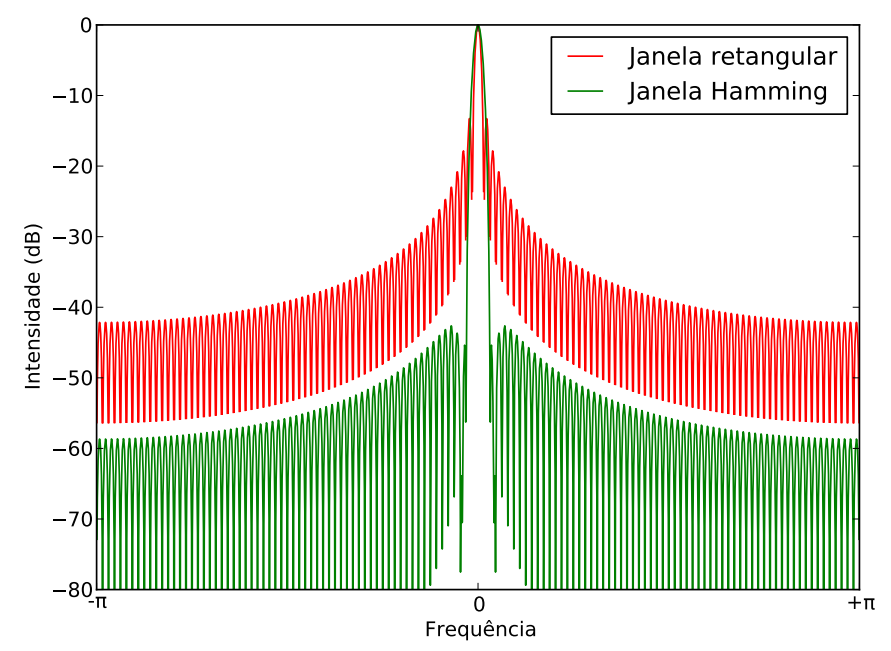

Figura 5 - Comparação da resposta em frequência entre janelas retangular e de Hamming.

A Figura 5 ilustra a resposta em frequência da janela Hamming comparada com a janela retangular. Os lobos laterais da janela de Hamming são várias ordens de grandeza menores que os da janela retangular. A janela Hamming foi escolhida dentre outras janelas disponíveis devido ao fato de ser otimizada para reduzir ao máximo o lobo lateral mais próximo (15), pois informações importantes para a assinatura do peixe pareciam estar localizadas em regiões próximas entre si no domínio da frequência.

Na Figura 6, pode-se observar a diferença, na prática, entre utilizar ou não uma janela de Hamming. São mostradas algumas assinaturas sobrepostas em um mesmo gráfico, computadas a partir de descargas de um mesmo peixe. As assinaturas computadas utilizando a janela retangular possuem artefatos que variam bastante entre descargas diferentes. Tais artefatos desaparecem quando é utilizada a janela de Hamming. 


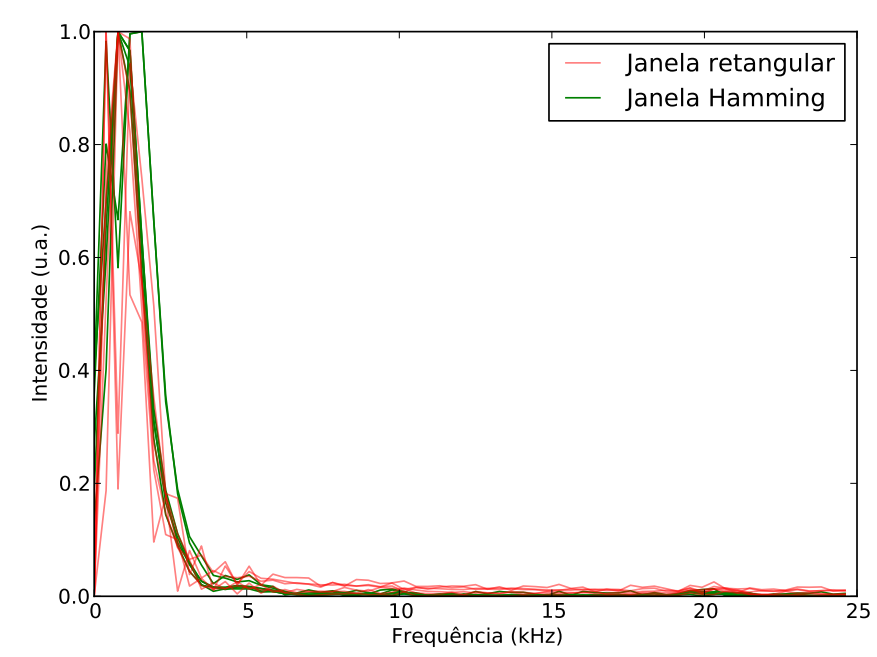

Figura 6 - Comparação entre assinaturas do peixe utilizando janelas retangular e de Hamming. Assinaturas computadas utilizando a janela de Hamming são mais fixas.
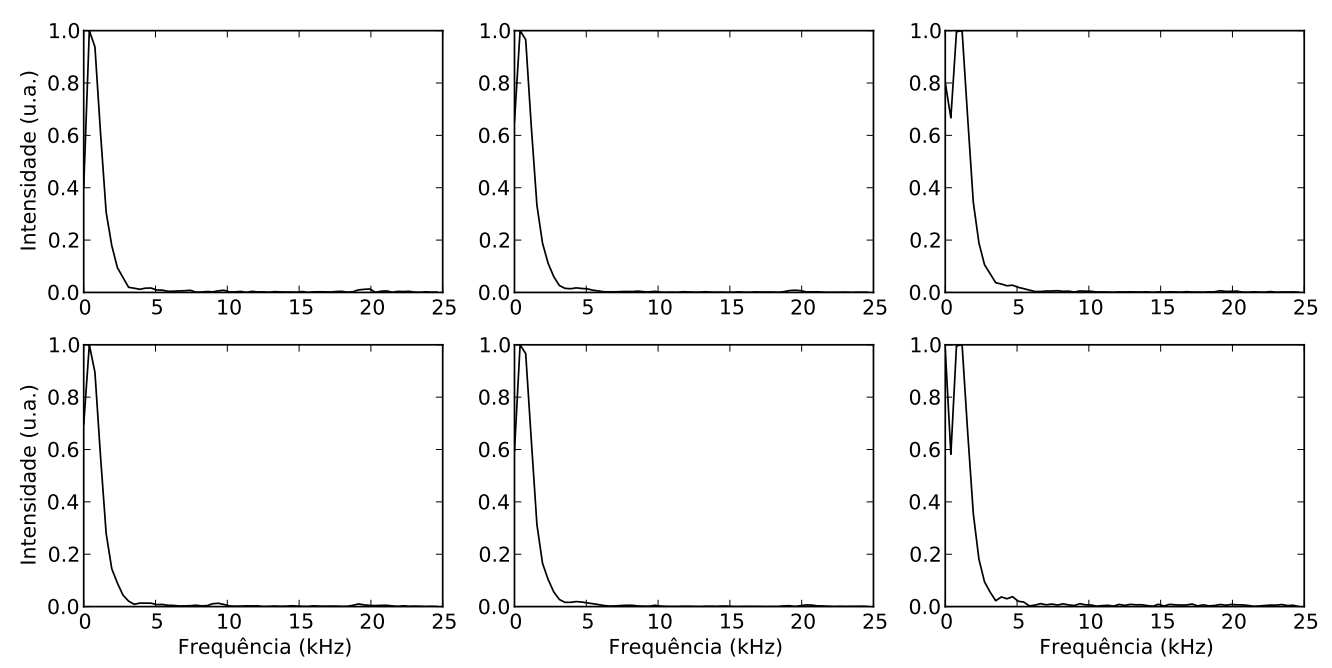

Figura 7 - Forma típica das assinaturas computadas utilizando a transformada de Fourier. Obtém-se um formato mais fixo que o observado no domínio do tempo.

A Figura 7 mostra as assinaturas computadas utilizando esta variação do método para as mesmas descargas apresentadas na Figura 3. Observa-se que o formato obtido é mais fixo do que aquele observado no domínio do tempo, sugerindo que este seja um bom passo inicial para a identificação dos peixes. 


\subsubsection{Transformada complexa de dupla árvore de pacote wavelet}

A transformada de Fourier não preserva nenhuma informação temporal a respeito do sinal original. Além disso, como descartamos totalmente a informação de fase, obtemos uma assinatura de somente 64 amostras usando tal variação do método. Levantou-se a hipótese, portanto, de que com alguma espécie de transformada wavelet seria possível extrair mais informações a partir do sinal, levando talvez a uma melhor eficácia de deteção.

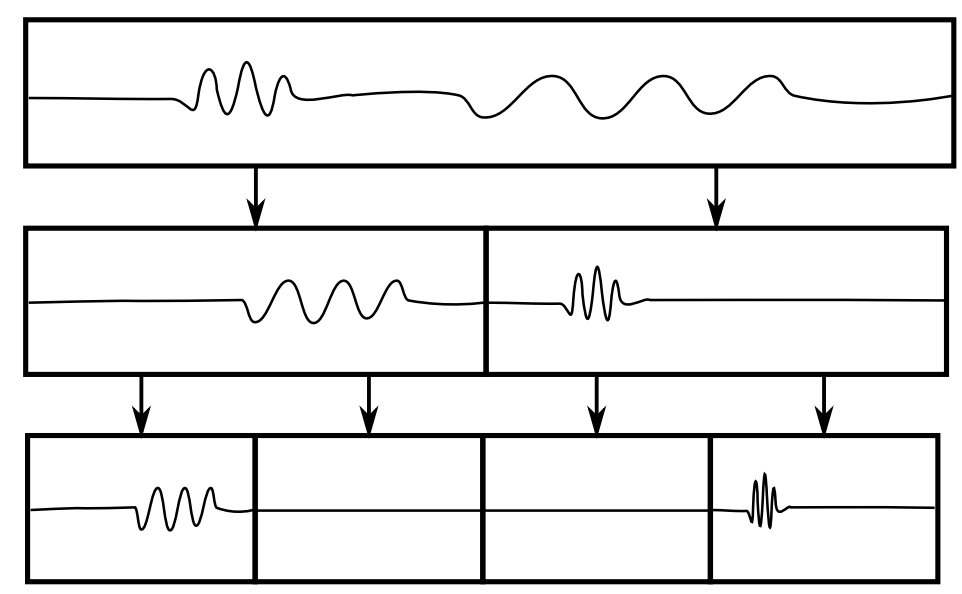

Figura 8 - Funcionamento de uma transformada de pacote wavelet. A transformada pode ser vista como uma árvore binária completa. A cada nível, perde-se resolução no tempo e ganha-se resolução em frequência.

O funcionamento básico de uma transformada wavelet é bastante simples. A transformada é composta de um par de filtros complementares, um passa-baixas e outro passaaltas. São realizadas diversas decomposições do sinal original utilizando esses filtros. A cada decomposição, metade do intervalo de frequências possível no sinal que está sendo decomposto passa pelo filtro passa-baixas, outra metade passa pelo passa-altas, e os sinais resultantes são sub-amostrados para a metade da taxa de amostragem original. Dessa forma, a cada decomposição, dobra a resolução em frequência, e a resolução em tempo é reduzida pela metade.

A transforma de pacote wavelet, mostrada na Figura 8, é uma espécie de transformada wavelet na qual o sinal original é decomposto desde a mínima resolução em frequência e máxima resolução em tempo até a mínima resolução em tempo e máxima resolução em 
frequência. A transformada forma uma estrutura em formato de árvore, na qual os dois filhos de cada folha correspondem à sua decomposição pelo par de filtros passa-baixas e passa-altas.
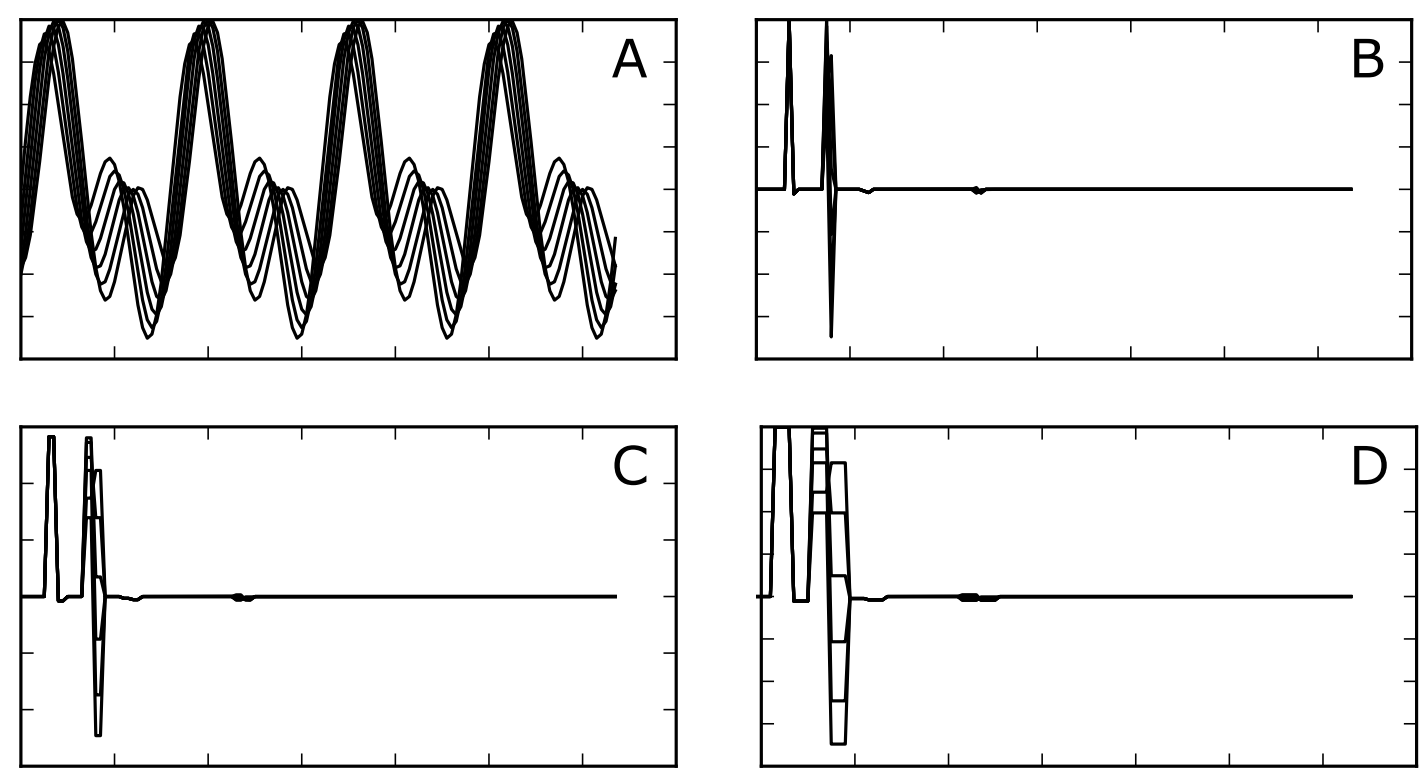

Figura 9 - $\quad$ Transformada de pacote wavelet em um sinal com diferença de fase variável entre componentes de frequência. A Sinais no domínio do tempo, compostos pela interferência entre duas senóides de frequências diferentes cuja diferença de fase é variada. B Decomposição dos sinais com uma transformada de pacote wavelet em nível máximo. C Decomposição no penúltimo nível. D Decomposição no antepenúltimo nível.

Entretanto, as transformadas wavelet comuns não são adequadas ao problema em questão, pois observamos que a diferença de fase entre componentes de frequência distintas varia de acordo com a posição do peixe, provavelmente devido a diferenças no tempo de propagação dos sinais produzidos pelos diversos segmentos de eletrócitos do corpo do animal (16).

As transformadas wavelet são extremamente sensíveis a esse tipo de variação, como mostra a Figura 9. Produzimos um sinal do tipo $\sin \left(\omega_{a} t\right)+\sin \left(\omega_{b} t+\phi\right)$ e calculamos sua transformada de pacote wavelet nos três últimos níveis. Conforme a diferença de fase $\phi$ varia, a transformada também varia, originando os artefatos observados na figura.

Para sanar este e outros problemas relacionados à transformada wavelet, foi desenvolvida a transformada wavelet complexa de dupla árvore (17). Essa transformada é cal- 
culada a partir de duas transformadas wavelet comuns, motivo do nome "dupla árvore". O par de filtros de cada árvore é projetado de forma que um deles seja aproximadamente igual ao outro atrasado de meia amostra. As amostras obtidas por meio de uma das árvores são tratadas como componentes reais da transformada total, e as da outra como componentes imaginárias. Dessa forma, a transformada total se torna aproximadamente analítica no plano complexo, ou seja, não há variações bruscas devido a diferenças de fase.

Porém, a transformada wavelet referida não é uma transformada "de pacote". Isso significa que a mesma decompõe sucessivamente apenas as componentes de baixa frequência, o que não gera uma árvore completa como a observada na Figura 8. Felizmente, a transformada em questão já foi estendida para o formato de pacote (11-12), dando origem à transformada complexa de dupla árvore de pacote wavelet ou, em inglês, dual-tree complex wavelet packet transform (DT-CWPT).

O cuidado adicional exigido por essa transformada é que certos ramos da árvore completa precisam ser decompostos por filtros wavelet comuns em vez dos pares de filtros
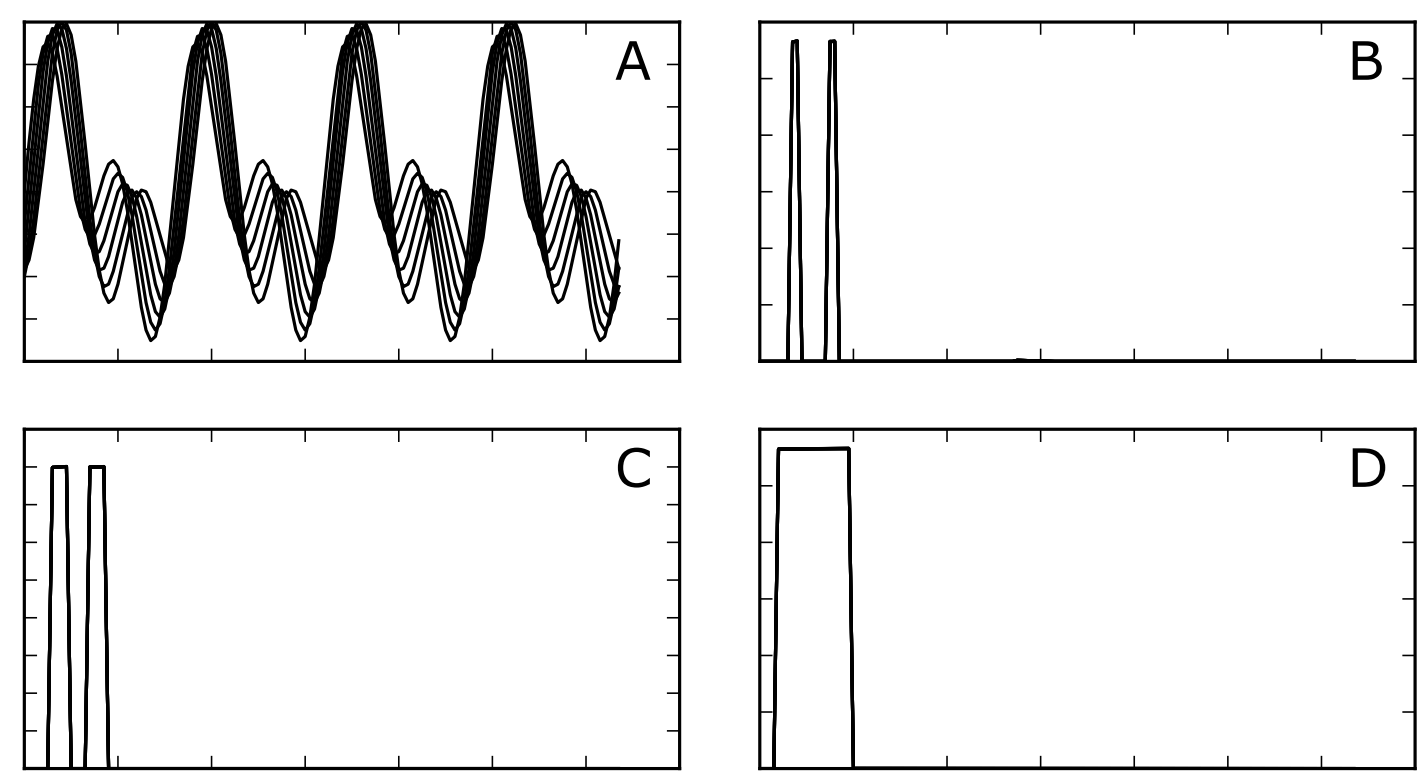

Figura 10 - Transformada complexa de dupla árvore de pacote wavelet em um sinal com diferença de fase variável entre componentes de frequência. A Sinais no domínio do tempo, compostos pela interferência entre duas senóides de frequências diferentes cuja diferença de fase é variada. B Decomposição dos sinais com uma transformada complexa de dupla árvore de pacote wavelet em nível máximo. C Decomposição no penúltimo nível. D Decomposição no antepenúltimo nível. 
atrasados de meia amostra. Isso deve ser feito quando certo nó já atingiu a condição mais próxima possível da analicitidade, e portanto pode ser decomposto como em uma transformada wavelet comum.

Na Figura 10, observamos o mesmo sinal da Figura 9 sendo decomposto agora pela DT-CWPT. Cada um dos três últimos níveis da transformada, apresentados na figura, permanece constante conforme a diferença de fase varia. Essa propriedade desejável é mantida pela DT-CWPT desde que o grau de precisão temporal correspondente ao nível em questão da transformada seja menor que o deslocamento temporal ocasionado pela diferença de fase.

Apesar de os coeficientes calculados pela DT-CWPT serem complexos, na figura mostramos apenas o módulo desses coeficientes, como é comum também na literatura. É importante notar que os coeficientes complexos são redundantes: é possível reconstruir o sinal original de posse apenas de suas partes reais ou imaginárias. Portanto, costumase utilizar somente o módulo dos coeficientes, pois é este que apresenta as propriedades desejáveis de invariância a deslocamentos e fases, dentre outras.

Por meio da DT-CWPT aplicada a uma janela de 128 amostras contendo uma descarga de órgão elétrico, obtemos árvores de sete níveis, o que nos dá 1024 amostras, contando com o sinal original, contendo uma análise tempo-frequência completa desse sinal. Todas essas amostras poderiam ser utilizadas para treinar um classificador supervisionado, porém isso tornaria o tempo de treinamento proibitivo quando utilizado algum dos classificadores do estado da arte. É preferível utilizar um grande número de exemplos para treinamento (permitindo uma boa estatística) e um bom classificador a usar um número reduzido de exemplos ou um classificador de baixa qualidade.

Por esse motivo, adaptamos o algoritmo de melhor base (18) para adequá-lo melhor ao problema de classificação supervisionada de sinais. O algoritmo foi proposto inicialmente para encontrar um conjunto de folhas de uma árvore wavelet que possuísse a menor entropia de Shannon (19) possível e que representasse o sinal sem redundância nem perda de informações com relação ao sinal original, ou seja, que fosse uma nova base para 
o espaço vetorial do problema. A minimização da entropia visa privilegiar folhas que contenham algumas amostras acentuadas e outras de valor desprezível. Essa técnica é bastante eficiente para compressão de dados, pois permite que apenas as amostras de valor acentuado sejam armazenadas para um certo sinal sem que o sinal posteriormente reconstruído sofra muita variação.
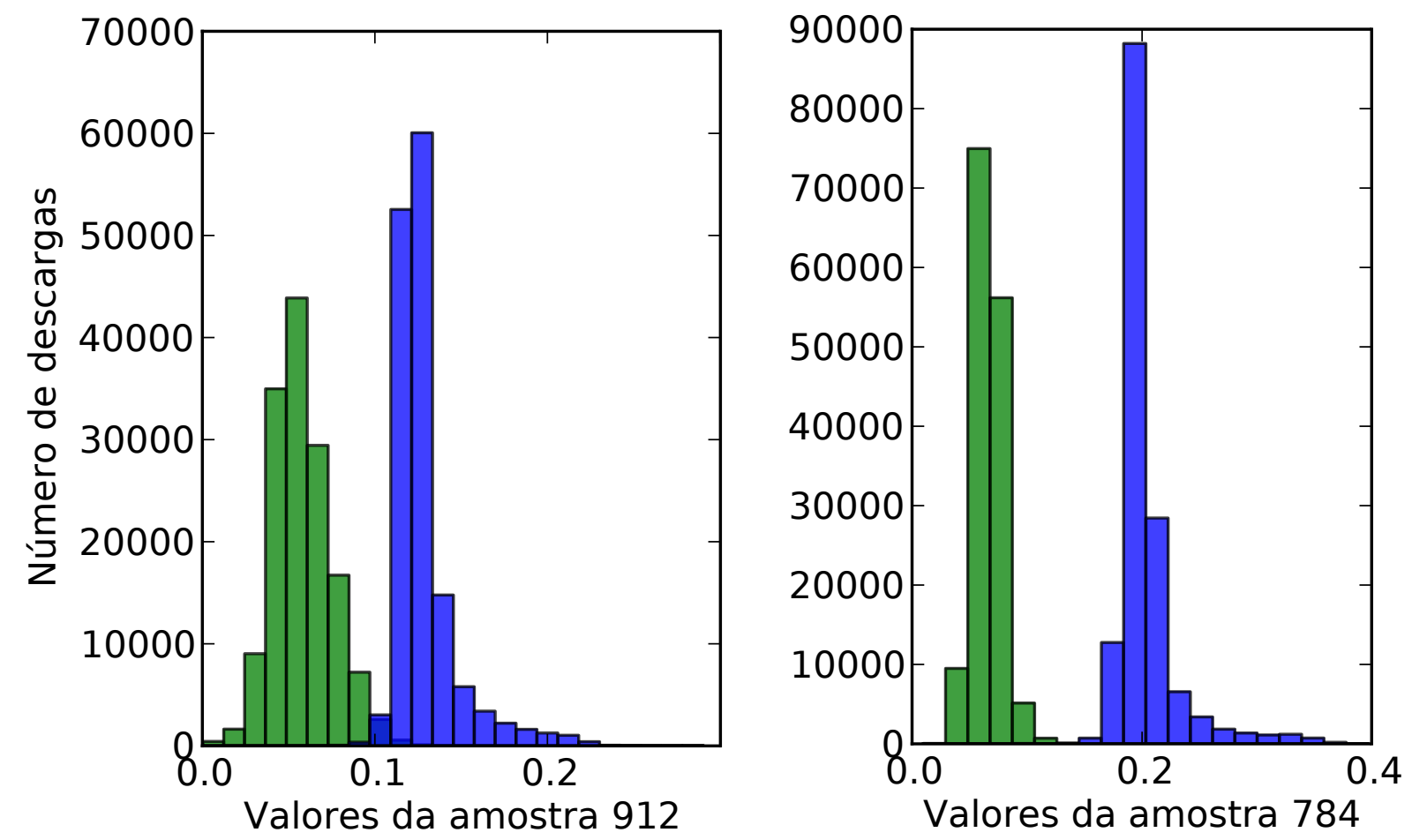

Figura 11 - Histogramas de amostras de níveis diferentes de uma DT-CWPT. A amostra 912 pertence ao último nível da transformada, enquanto a 784 pertence ao penúltimo. As barras verdes correspondem a um dos peixes, e as barras azuis ao outro. Tomando como base da classificação a amostra 784, a probabilidade de confundir um peixe com o outro é menor que com a amostra 912.

Entretanto, a métrica que nos interessa ao distinguir sinais entre duas classes é o quanto as amostras de um diferem das amostras do outro. Na Figura 11, nota-se um caso no qual o uso de uma das amostras do penúltimo nível é preferível ao uso da amostra correspondente do último nível. Propomos assim um algoritmo que calcula a média e o desvio padrão de cada amostra da árvore completa. Esses dois valores são utilizados para aproximar a distribuição de probabilidades de cada amostra como uma distribuição normal.

O mesmo método de (18) é utilizado, então, para escolher as melhores folhas da 
árvore. Percorre-se a árvore do último nível até o primeiro, guardando como estado quais são as folhas atualmente tidas como ótimas. Inicialmente, assume-se que as folhas do último nível são as ótimas. A cada nível, calcula-se para cada amostra de cada folha uma métrica baseada na área de sobreposição entre as funções gaussianas da distribuição normal das amostras de cada peixe. Caso a soma da métrica das amostras de uma folha seja menor que a soma da métrica das folhas atualmente tidas como ótimas e que estejam abaixo da folha em questão na hieraquia da árvore, essa folha passa a ser tida como ótima.
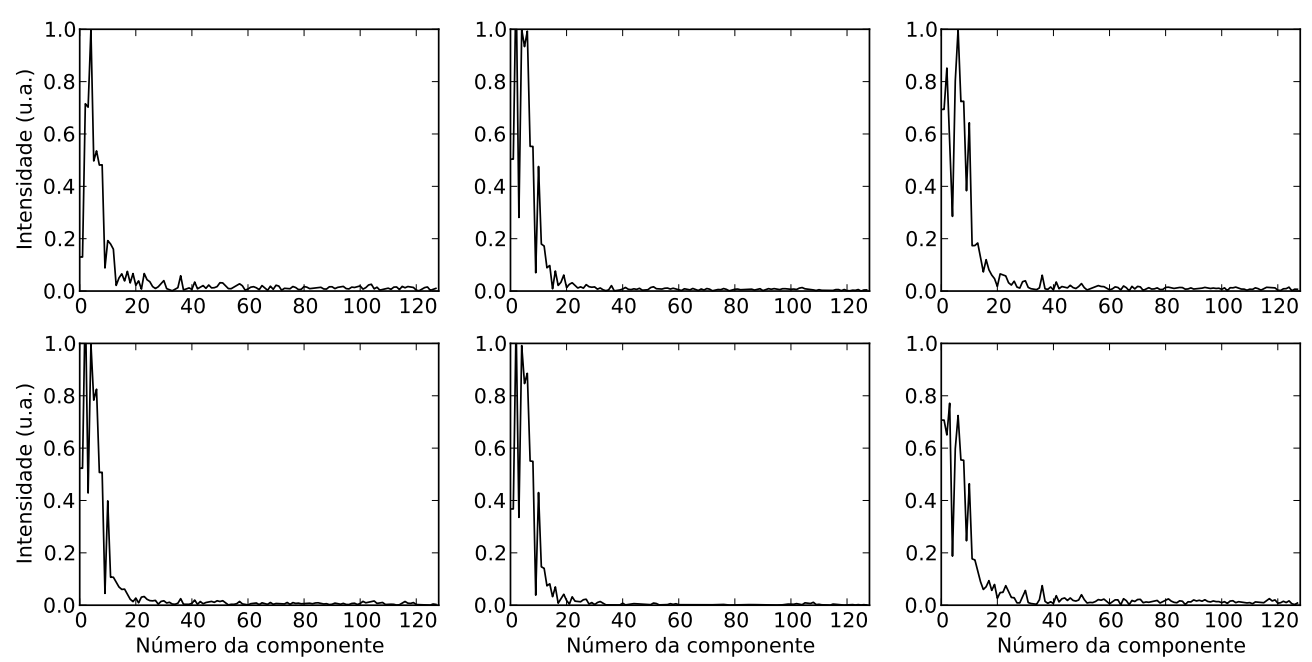

Figura 12 - Forma típica das assinaturas computadas utilizando a DT-CWPT.

Na Figura 12, mostramos as assinaturas computadas por esta variação do método para as mesmas descargas apresentadas na Figura 3. São mostradas apenas as amostras selecionadas pelo algoritmo de melhor base descrito, que maximizam a distinguibilidade destas assinaturas com as do outro peixe.

\subsubsection{Comparação visual entre os dois métodos de assinatura}

As Figuras 13 e 14 apresentam a superposição em um mesmo gráfico de algumas assinaturas computadas por meio da transformada de Fourier e por meio da transformada complexa de dupla árvore de pacote wavelet, respectivamente. 


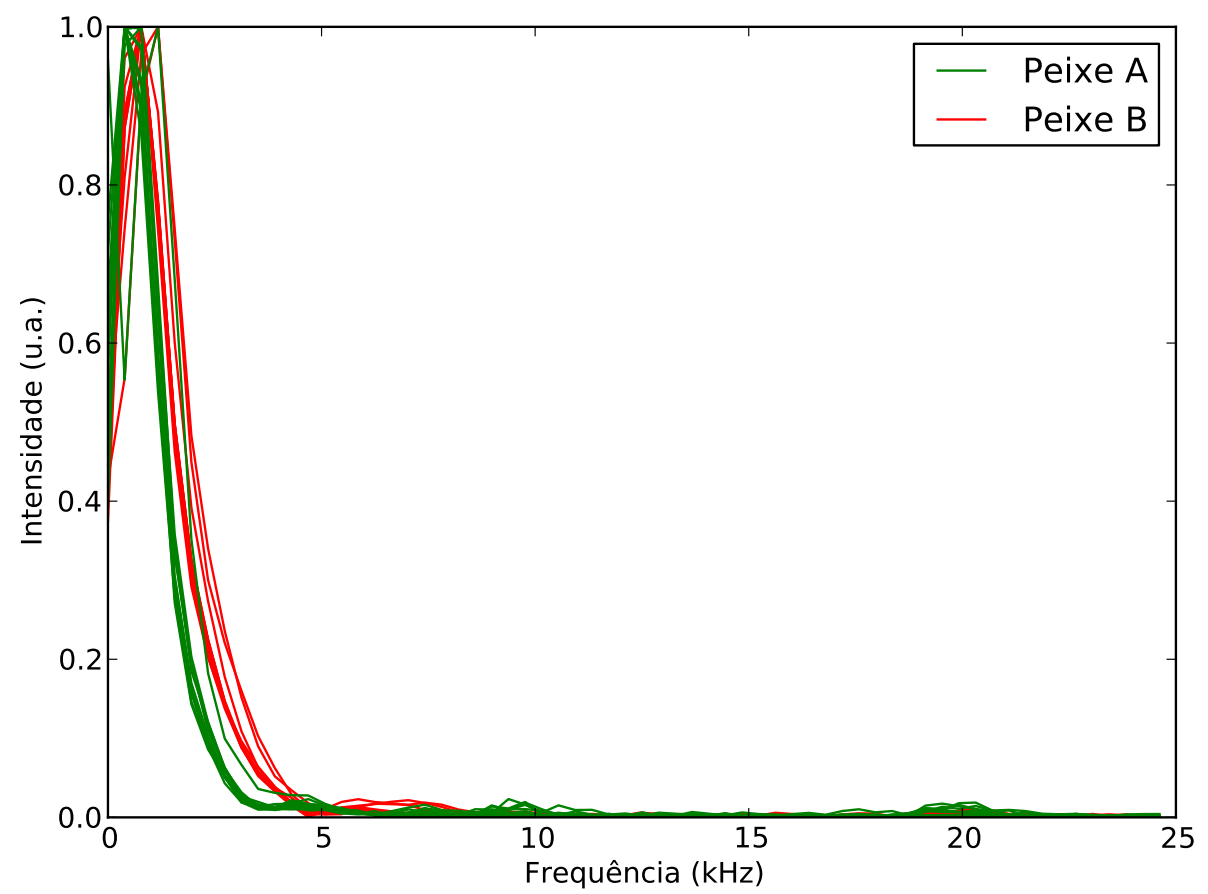

Figura 13 - Comparação entre assinaturas de dois peixes calculadas por FFT.

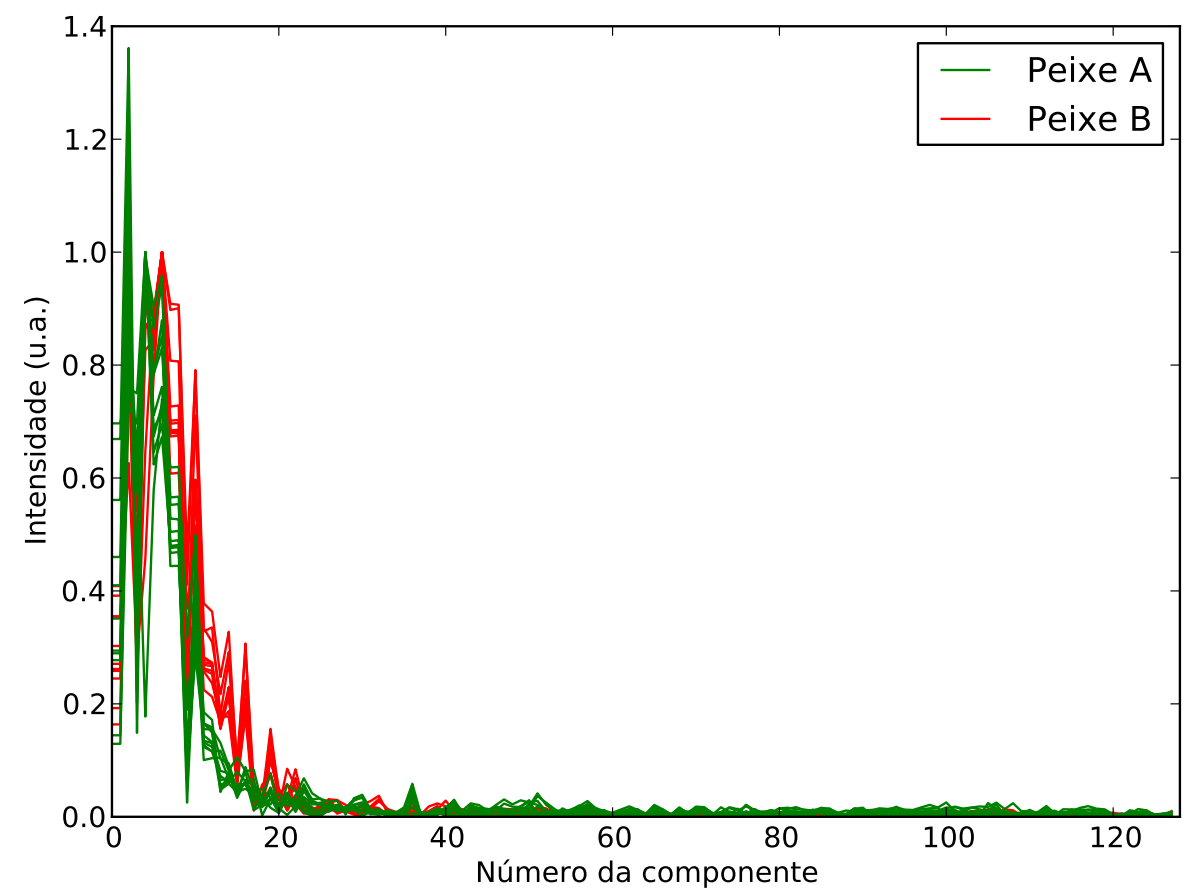

Figura 14 - Comparação entre assinaturas de dois peixes calculadas por DT-CWPT. 


\subsection{Máquina de vetores de suporte}

Para identificar o peixe de origem de uma assinatura, utilizamos o método de classificação supervisionada denominado máquina de vetores de suporte (13-14), ou support vector machine (SVM). Apesar de termos nos esforçado bastante para que as assinaturas possuíssem diferenças significativas de um peixe para outro, o uso de um bom método de classificação é essencial para garantir uma boa margem de generalização. Ou seja, permitir que o método se comporte bem em situações ligeiramente diferentes daquelas passadas durante a aquisição das descargas quando os peixes estavam separados um do outro.

A máquina de vetores de suporte é um método bastante consagrado na literatura. Apesar de não ser considerado atualmente o melhor método disponível para classificação supervisionada (20), sua eficácia é geralmente bastante próxima dos métodos do estado da arte, tais como bagging, double bagging e random forests. A vantagem de se usar a SVM reside no fato de existirem excelentes implementações da mesma em código aberto, bastante testadas e utilizadas pela comunidade científica (21-22).

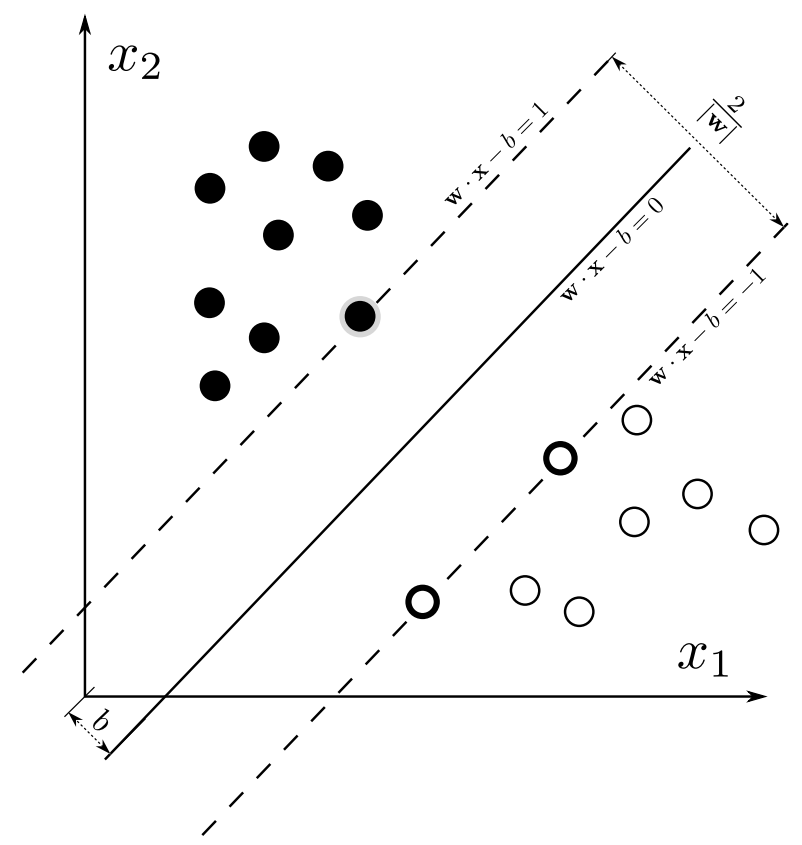

Figura 15 - Funcionamento de uma máquina de vetores de suporte. Pontos pertencentes a classes distintas são divididos por um hiperplano de separação máxima. Os pontos em destaque, sobre a margem, correspondem aos denominados vetores de suporte. 
O funcionamento básico da SVM é mostrado na Figura 15. O objetivo da SVM é separar por um hiperplano em um espaço n-dimensional os pontos pertencentes a exemplos de treinamento de classes distintas. O critério utilizado para definir o melhor hiperplano é que este seja um hiperplano de separação máxima. Ou seja, na figura, minimiza-se $|\mathbf{w}|$. Isso permite ao método possuir uma boa margem de generalização ao tratar casos que não estejam previamente listados nos exemplos de treinamento. Na prática, é realizada a seguinte minimização:

$$
\begin{array}{r}
\min _{\mathbf{w}, \xi}\left\{\frac{1}{2}|\mathbf{w}|^{2}+C \sum_{\substack{i=1 \\
\text { sujeito a }}}^{n} \xi_{i}\right\} \\
y_{i}\left(\mathbf{w} \cdot \mathbf{x}_{\mathbf{i}}-b\right) \geq 1-\xi_{i}, \quad \xi_{i} \geq 0
\end{array}
$$

Onde $C$ é um parâmetro ajustável que controla qual peso é dado no processo de otimização à classificação incorreta de exemplos do conjunto de treinamento. O vetor w, que define a "direção" do hiperplano, é resolvido de forma que o mesmo seja uma combinação linear de pontos pertencentes aos exemplos de treinamento. Na prática, a maioria dos coeficientes da combinação linear serão nulos. Os vetores que acabarem associados a coeficientes não nulos são chamados de vetores de suporte.

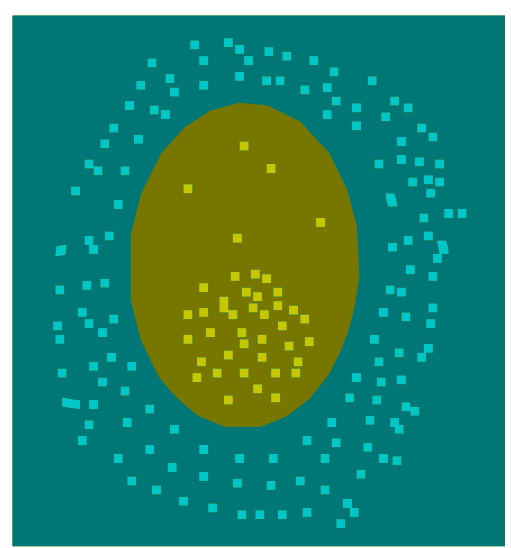

Figura 16 - Exemplo de pontos linearmente inseparáveis sendo utilizados para treinar uma SVM. Usando o kernel RBF, a SVM encontrou um hiperplano capaz de separar os pontos em um espaço de infinitas dimensões. A fronteira correspondente no espaço original de duas dimensões é mostrada na figura. 
Para permitir que a SVM possa separar casos não linearmente separáveis, é introduzido o "truque do kernel", que consiste em trocar o produto interno das equações dos hiperplanos por um kernel $K\left(\mathbf{x}_{\mathbf{i}}, \mathbf{x}_{\mathbf{j}}\right)$ que seja equivalente ao produto interno dos vetores representados em um espaço vetorial de mais dimensões que o espaço original. Como as componentes dos vetores do espaço de mais dimensões não são utilizadas diretamente, mas sim apenas seu produto interno, que é calculado indiretamente pelo kernel, pode-se mapear os vetores até mesmo em espaços de infinitas dimensões, onde é possível que o problema se torne linearmente separável, como no exemplo da Figura 16.

O kernel escolhido para nosso método foi o RBF (Radial Basis Function), largamente utilizado na literatura de aprendizagem de máquina por se tratar de um kernel que, dependendo dos parâmetros escolhidos, pode comportar-se de maneira similar a outros tipos de kernel conhecidos (23-24). O RBF é definido pela seguinte equação:

$$
K\left(\mathbf{x}_{\mathbf{i}}, \mathbf{x}_{\mathbf{j}}\right)=\exp \left(-\gamma\left|\mathbf{x}_{\mathbf{i}}-\mathbf{x}_{\mathbf{j}}\right|\right)
$$

Onde $\gamma$ é um parâmetro ajustável, que geralmente é testado para se encontrar qual valor faz com que a SVM tenha melhor eficácia para cada problema. 


\section{Desenvolvimento}

\subsection{Aspectos gerais de implementação}

Os programas desenvolvidos foram implementados na linguagem C. Para facilitar uma futura adaptação para o Comedi, biblioteca de drivers para uso de placas de aquisição no Linux, os arquivos de dados são lidos por uma interface de software que imita uma placa de aquisição. Desta forma, todos os algoritmos foram projetados para lidar linearmente com os dados de aquisição, realizando sua leitura somente por meio de buffers.

A adaptação para o Comedi será importante para trabalhos futuros, pois aquisições de pouco mais de 15 minutos geram arquivos de quatro gigabytes no software utilizado atualmente (Dasylab). Além de se tratar de uma quantidade muito grande de dados, o Dasylab corrompe arquivos de tamanho superior a quatro gigabytes, por utilizar internamente ponteiros de 32 bits. Com a adaptação para o Comedi, tal problema seria sanado e, além disso, haveria a opção de se salvar, caso desejado, somente os instantes de ocorrência das descargas e o peixe de origem detetado, poupando espaço em disco durante aquisições longas.

Para montar janelas de 128 amostras a serem passadas para o método de assinatura, utilizamos um discriminador simples, baseado em um limiar de amplitude. Utilizamos o valor padrão de 0,5 volts, que nos experimentos mostrou-se suficiente para ativar o discriminador mesmo quando o peixe está situado no meio do aquário. Este valor, porém, foi deixado configurável por linha de comando.

A transformada rápida de Fourier, utilizada no primeiro método de assinatura, foi implementada utilizando a biblioteca de código aberto FFTW (25).

A implementação da transformada complexa de dupla árvore de pacote wavelet foi realizada do zero, tendo como base o artigo (11). Foram desenvolvidas rotinas para o cálculo de uma árvore completa da transformada, para cálculo da transformada inversa 
de um certo nível da árvore, para decomposição apenas até um certo conjunto de folhas da árvore, para a inversa dessa decomposição, e para determinação da melhor base (best basis) utilizando uma métrica genérica.

O método usado para assinatura, baseado em transformada de Fourier ou wavelet, pode ser escolhido em tempo de compilação no arquivo global.h do código fonte do programa.

A implementação da máquina de vetores de suporte adotada foi a biblioteca libsvm (21-22), também de código aberto.

\subsection{Implementação do programa de treino}

O software de treino recebe por linha de comando o nome de dois arquivos distintos, cada um contendo dados de aquisição de peixes diferentes, e o nome desejado para os arquivos de saída, nos quais são gravados os dados do modelo.

O programa executa o discriminador, detetando todos os canais que estejam acima do limiar de deteção e que estejam abaixo do limiar de saturação da placa de aquisição, passando as janelas de 128 amostras para o método de assinatura escolhido, cujos resultados são salvos em arquivos temporários. Para uma aquisição de cerca de 15 minutos, o tamanho típico de cada um desses arquivos é de 40 megabytes, quando utilizado o método de assinatura baseado em FFT, ou de 600 megabytes, quando utilizado o método de assinatura baseado em DT-CWPT.

Após processadas todas as janelas, o programa calcula a média e o desvio padrão de cada uma das amostras. Se escolhido o método baseado em DT-CWPT, esses valores são utilizados para determinar a melhor base de representação dos sinais, com o algoritmo descrito neste trabalho. Essa base é salva em um arquivo chamado modelo. bestbasis.

Independente do método de assinatura escolhido, o próximo passo é computar fatores de escala para cada uma das amostras, de forma a situá-las em uma faixa típica de 
valores entre -1 e 1, como recomendado pela documentação da libsvm, com o objetivo de evitar problemas numéricos (21). Na determinação dos valores mínimo e máximo de cada amostra, que servem de base para o cálculo do fator de escala, desconsideramos valores que estejam fora da faixa entre $\mu-3 \sigma$ e $\mu+3 \sigma$, onde $\mu$ denota a média da amostra, e $\sigma$ seu desvio padrão. Isso é feito para evitar que valores atípicos (outliers), resultantes por exemplo de um único evento de ruído impulsivo, afetem os fatores de escala associados a toda a aquisição. Os fatores são salvos, então, em um arquivo chamado modelo.scale.

Em seguida, os valores dos arquivos temporários são lidos novamente, aplicando o fator de escala e, no caso da DT-CWPT, escolhendo as amostras pertencentes à melhor base, para montar uma estrutura de treinamento no formato requerido pela libsvm.

É efetuado, então, o treinamento de uma SVM em modo de validação cruzada, utilizando parâmetros $C$ e $\gamma$ fornecidos por linha de comando. Pode ser fornecido também um intervalo de parâmetros a serem testados. O modo de validação cruzada divide o conjunto de dados em cinco partes. Em seguida, o treinamento é executado cinco vezes, cada vez desconsiderando uma das partes do conjunto de dados. Após cada treinamento, verifica-se a quantidade de dados da parte desconsiderada que são reconhecidos corretamente pelo modelo SVM resultante. A porcentagem total de acertos dá uma ideia da qualidade do modelo SVM. Caso tenha sido fornecido um intervalo de parâmetros a serem testados, o programa executará em paralelo vários desses testes de validação cruzada, verificando qual conjunto de parâmetros $C$ e $\gamma$ fornece a melhor taxa de acerto.

Por fim, uma vez exibida ao usuário a taxa de acerto da validação cruzada, o programa treina um modelo SVM utilizando todos os dados disponíveis. Esse modelo é salvo em um arquivo chamado modelo.svm. 


\subsection{Implementação do programa de reconhecimento}

O software de reconhecimento recebe por linha de comando o nome dos arquivos pertencentes ao modelo e o nome de um arquivo de aquisição contendo o sinal capturado em um experimento com dois peixes.

O programa executa o discriminador, detetando todos os canais que estejam acima do limiar, e passando cada uma das janelas de 128 amostras para o método de assinatura escolhido. O resultado recebe os mesmos fatores de escala que foram aplicados sobre os dados de treinamento, e em seguida é fornecido ao modelo SVM, que retorna qual peixe foi detetado como tendo originado aquela descarga. O dado sobre o peixe de origem é colocado em uma fila, associado a informações sobre o instante de ocorrência da descarga, o canal, a amplitude máxima da janela, e a quantidade de amostras acima do limiar de saturação da placa.

Assim que todos os canais forem discriminados, e assim que se passarem pelo menos 5 milissegundos desde o último disparo enfileirado, todos os elementos contidos na fila são processados por um algoritmo que ordena as descargas, de forma a agrupar as descargas do mesmo peixe que tenham sido detetadas próximas em um intervalo de no máximo 5 milissegundos. Esse valor de intervalo foi escolhido pois, em experimentos utilizando outros métodos, nunca foi observada uma taxa de disparo acima de $200 \mathrm{~Hz}$ para peixes da espécie Gymnotus carapo. O programa dá como saída, então, todos os dados que haviam sido inseridos na fila, com um grupo de dados correspondentes a uma mesma descarga por linha, ordenados do canal que tenha apresentado menor número de amostras saturadas ou maior amplitude ao canal que tenha apresentado maior número de amostras saturadas ou menor amplitude. 


\section{Resultados}

\subsection{Validação cruzada e reconhecimento de um peixe sozinho}

O software de treino foi testado com quatro peixes distintos de tamanho similar, cujos dados foram fornecidos ao programa par a par. Estavam disponíveis aquisições de pelo menos 15 minutos de dois desses peixes. Dos outros dois, possuíamos apenas aquisições de cerca de um minuto.

Foi possível obter 100,00\% de acerto no teste de validação cruzada, efetuado pelo próprio programa de treino, para todos os pares de peixes testados, com ambos os métodos de assinatura. Valores dos parâmetros da SVM que geraram bons resultados durante o treino foram $C=2^{7}, \gamma=2^{-11}$, em conjunto com o método de assinatura baseado em FFT, e $C=2^{5}, \gamma=2^{-7}$, com o método de assinatura baseado na DT-CWPT.

No total, estavam disponíveis cerca de uma hora de aquisições de um dos peixes sozinho no aquário. O reconhecimento foi testado sobre esses dados, utilizando um modelo treinado para distinguir este peixe do outro do qual também estavam disponíveis mais de 15 minutos de aquisição. A taxa de acerto foi sempre superior a 99,9\%, independente do método de assinatura utilizado. Os locais onde ocorriam erros foram verificados nos arquivos de aquisição originais, constantando-se que os mesmos eram devido à saturação dos canais da placa de aquisição.

Tais problemas graves de saturação ocorrem quando o peixe se aproxima muito do eletrodo que é utilizado como referência, o que faz com que seu sinal seja subtraído dos demais eletrodos, que ficam todos saturados (acima de 10 volts ou abaixo de -10 volts). Portanto, para a melhoria dos experimentos, é sugerida uma modificação no hardware de aquisição: acrescentar um segundo eletrodo de referência localizado no canto do aquário oposto ao da atual referência. 


\subsection{Avaliação da resistência a ruídos}

Apesar de os dados de aquisição utilizados na avaliação do método apresentarem um ruído característico de indução da rede elétrica com amplitude pico-a-pico de aproximadamente 0,2 volts, as altas taxas de acerto discutidas no tópico anterior foram possíveis mesmo utilizando um valor de 0,5 volts como limiar do discriminador.

Entretanto, é interessante avaliar como a taxa de acerto varia conforme é adicionado ainda mais ruído aos sinais originais. Para isso, adicionamos ruído branco gaussiano a janelas previamente discriminadas dos arquivos de aquisição de cada peixe sozinho. Para cada valor da relação entre sinal original e ruído adicional acrescentado, verificamos qual é a taxa de acerto do reconhecimento, utilizando cada um dos dois métodos de assinatura.

O resultado é mostrado na Figura 17. Ambos os métodos suportaram até cerca de -25 dB de ruído adicional sem perder significativamente a precisão. O método baseado na FFT mostrou-se mais robusto quando submetido a condições mais severas de ruído.

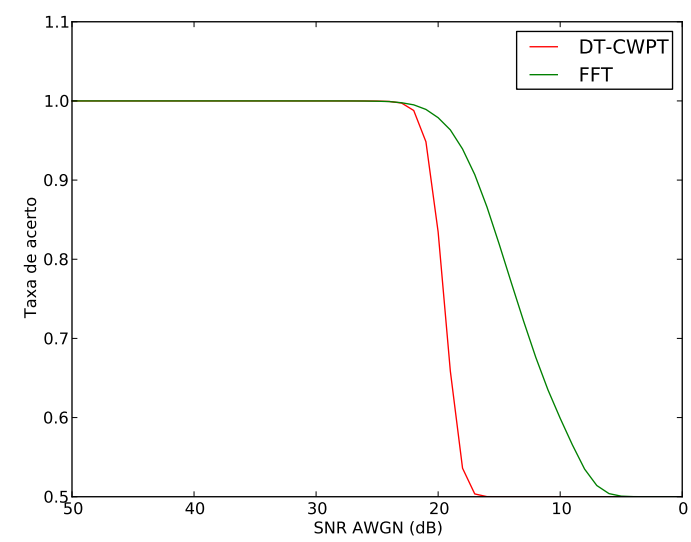

Figura 17 - Resistência dos métodos a ruído branco aditivo gaussiano. Adiciona-se ainda mais ruído ao sinal original dos peixes, e verifica-se a taxa de acerto dos métodos para cada valor da relação sinal-ruído.

Outro teste interessante é adicionar ao sinal de um peixe o sinal do outro, como se este fosse ruído, para tentar prever como os modelos se comportam no caso de descargas simultâneas. A Figura 18 mostra o gráfico correspondente. Nesse caso, o comportamento de ambos os métodos é bastante parecido, com a DT-CWPT apresentando uma taxa de 


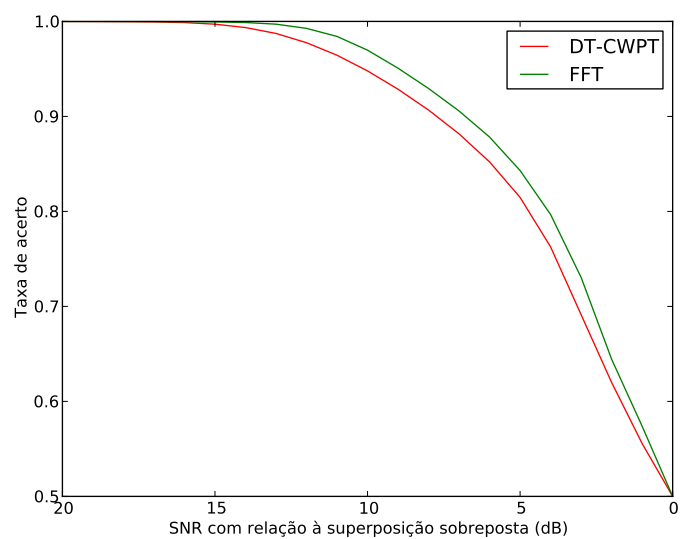

Figura 18 - Resistência dos métodos a sobreposição com descarga de outro peixe. Adiciona-se como "ruído" ao sinal de um peixe o sinal do outro, e vice-versa, verificando-se a taxa de acerto dos métodos para cada valor da relação sinal-ruído.

acerto ligeiramente menor.

Caso o mesmo teste seja repetido, porém deslocando o sinal do segundo peixe de 16 amostras ( $\frac{1}{8}$ da janela) antes de somá-lo, os resultados da Figura 19 são obtidos.

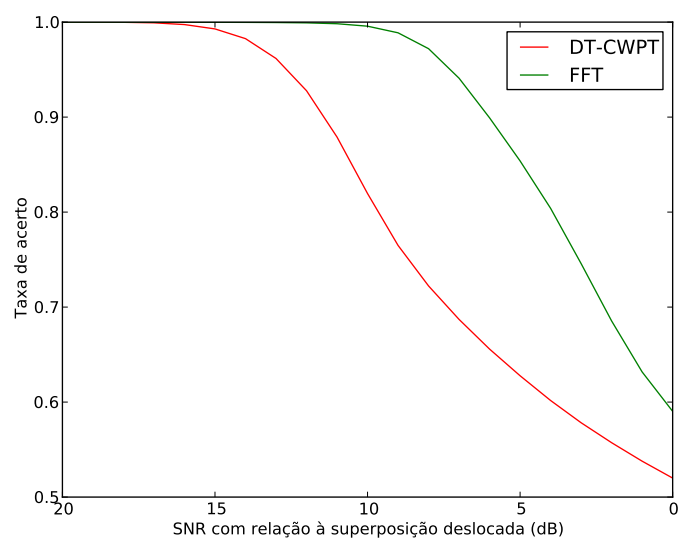

Figura 19 - Resistência dos métodos a sobreposição com descarga deslocada de outro peixe. Adiciona-se como "ruído" ao sinal de um peixe o sinal do outro deslocado de 16 amostras, e vice-versa, verificando-se a taxa de acerto dos métodos para cada valor da relação sinal-ruído.

Novamente, o método baseado em DT-CWPT apresenta uma taxa de acerto menor que o baseado em FFT. Porém, nos casos de sobreposição entre descargas, o erro não é necessariamente maléfico. Como o programa de reconhecimento avalia todos os canais que ultrapassarem o limiar do discriminador, o erro causado por uma sobreposição pode 
ajudá-lo a percebê-la. Por exemplo, caso exista uma probabilidade de $50 \%$ de errar a classificação de certa descarga que esteja sobreposta a outra, é provável que uma das descargas seja reconhecida em aproximadamente metade dos canais, e nos demais canais seja identificada a outra.

\subsection{Estimativa do erro real do método}

Para validar o método e estimar o erro que ocorreria com dois peixes em um mesmo aquário, realizamos um experimento no qual um estímulo previamente gravado foi reproduzido para um peixe por meio de um dipolo elétrico colocado na água.

Foram gravados cerca de 15 minutos de descargas do peixe sozinho no aquário, 10 minutos de descargas do dipolo emitindo o estímulo e 15 minutos de descargas do peixe junto com o dipolo. O treinamento resultou em validação cruzada de 100,00\%, independente do método de assinatura.

Os dados de saída do programa de reconhecimento foram processados para identificar se o sinal do estímulo, que disparava em instantes de tempo conhecidos, era detetado corretamente. Verificou-se assim apenas 0,02\% de erro quando utilizada assinatura baseada em DT-CWPT, e 0,12\% de erro quando utilizada a FFT.

Entretanto, ao observar os gráficos de intervalos entre descargas das Figuras 20 e 21, percebe-se que o erro não está distribuído igualmente entre o estímulo e o peixe real. Vários pontos correspondentes ao peixe saem subitamente da curva e ficam espalhados pelo gráfico. Alguns desses pontos foram verificados visualmente no arquivo original de aquisição, constatando-se que se tratavam de descargas simultâneas do estímulo e do

peixe. É razoável afirmar que praticamente todos esses pontos compartilham do mesmo problema, pois os erros de deteção de descargas do peixe cessam logo que o estímulo acaba. Além disso, o valor de intervalo entre descargas correspondente a esses pontos é aproximadamente o dobro do valor do ponto anterior a cada um deles, indicando que, se 


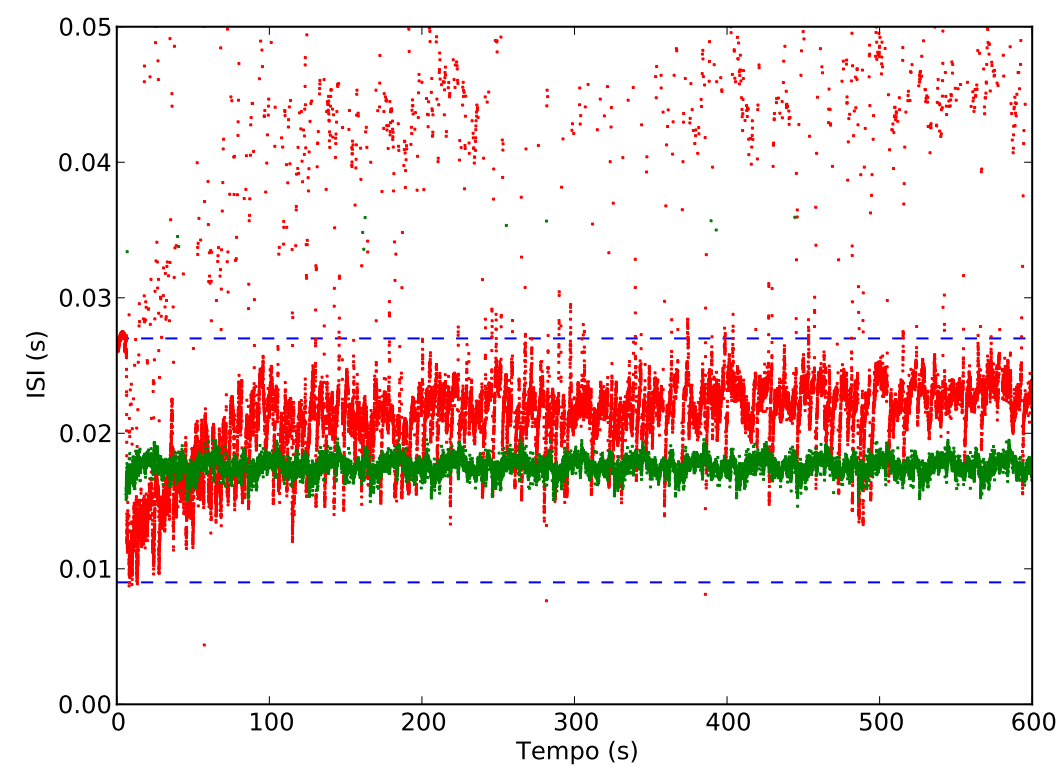

Figura 20 - Intervalos entre descargas em experimento com estímulo e peixe real, usando assinatura DT-CWPT. Os dados em verde correspondem a deteções do estímulo, e dados em vermelho a deteções do peixe real. Linhas pontilhadas em azul delimitam aproximadamente os acertos.

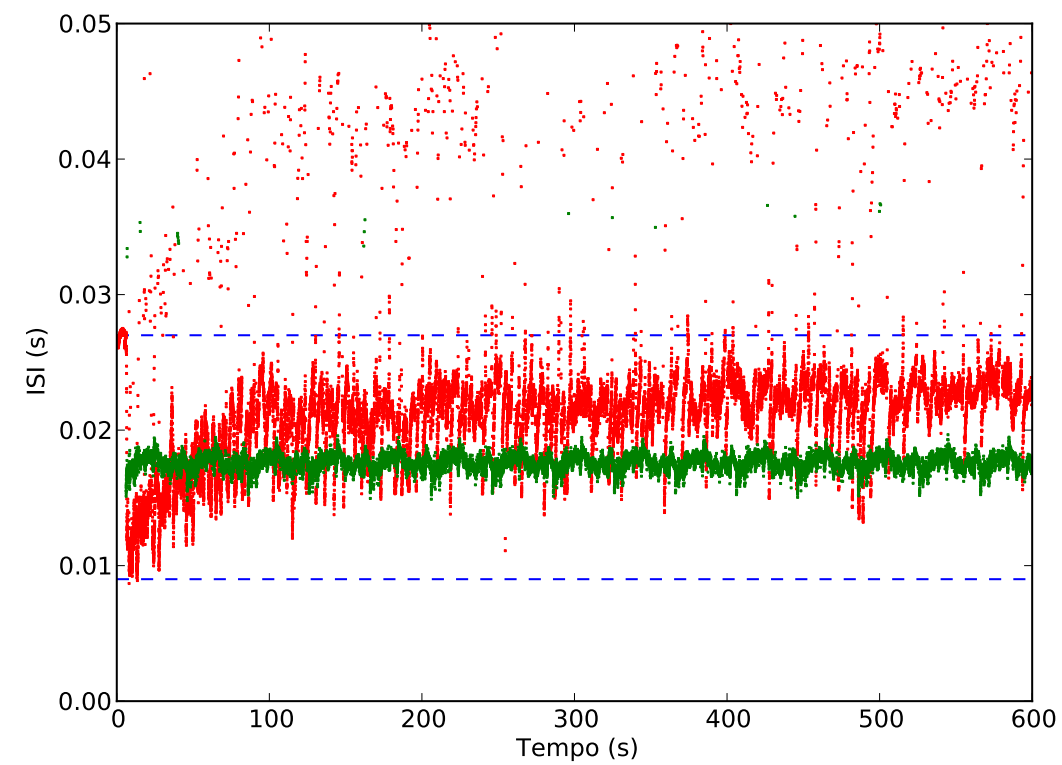

Figura 21 - Intervalos entre descargas em experimento com estímulo e peixe real, usando assinatura FFT. Os dados em verde correspondem a deteções do estímulo, e dados em vermelho a deteções do peixe real. Linhas pontilhadas em azul delimitam aproximadamente os acertos. 
a taxa de disparo variou pouco, exatamente uma descarga deixou de ser identificada.

Para estimar o erro em cada caso, contamos a quantidade de pontos vermelhos de cada gráfico contidos fora da região delimitada pelas linhas pontilhadas em azul. Para o experimento com assinatura baseada em FFT, estimou-se 3,5\% de erro, e para a DTCWPT, $4,5 \%$.

Todavia, não podemos afirmar que a FFT terá sempre eficácia maior que a DT-CWPT. Também não é negada por esse caso a hipótese levantada para a Figura 19, de que erros ocasionados por sobreposição de descargas podem ser benéficos. Ressaltamos que aqui os dados e o modelo treinado são outros. O gráfico equivalente ao da Figura 19 para este experimento é apresentado na Figura 22. Neste caso, a FFT possui, a princípio, uma taxa de acerto levemente inferior à DT-CWPT quando há uma descarga deslocada sobreposta.

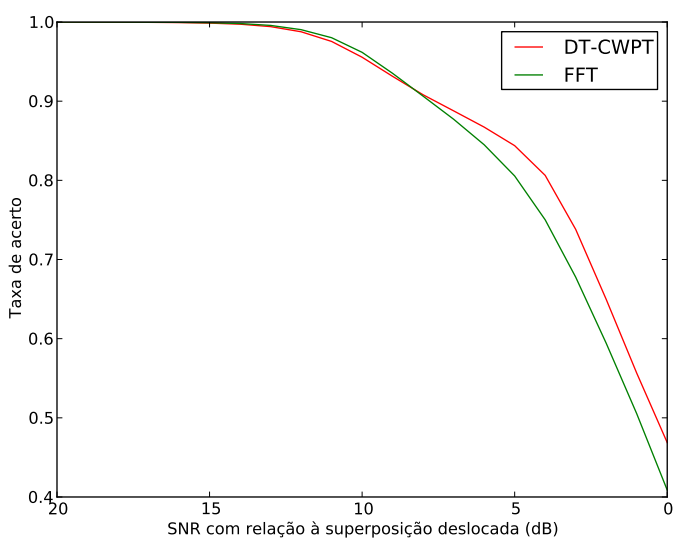

Figura 22 - Resistência a sobreposição com descarga deslocada no modelo do peixe e do estímulo. Adiciona-se como "ruído" ao sinal do peixe o sinal do estímulo deslocado de 16 amostras, e vice-versa, verificando-se a taxa de acerto dos métodos para cada valor da relação sinal-ruído.

\subsection{Experimentos preliminares com dois peixes}

Por fim, foram realizados experimentos preliminares com dois peixes em um mesmo aquário. As Figuras 23 e 24 mostram um mesmo trecho processado pelo método com assinaturas baseadas em FFT e DT-CWPT, respectivamente. 


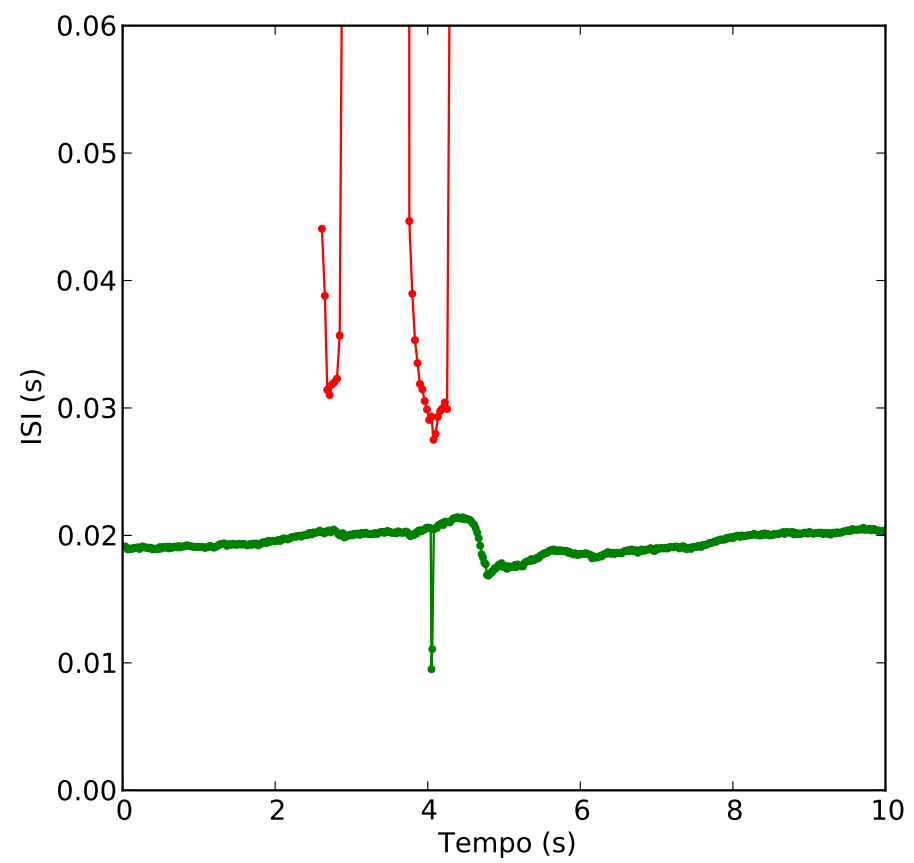

Figura 23 - Intervalos entre descargas em experimento com dois peixes, usando assinatura FFT.

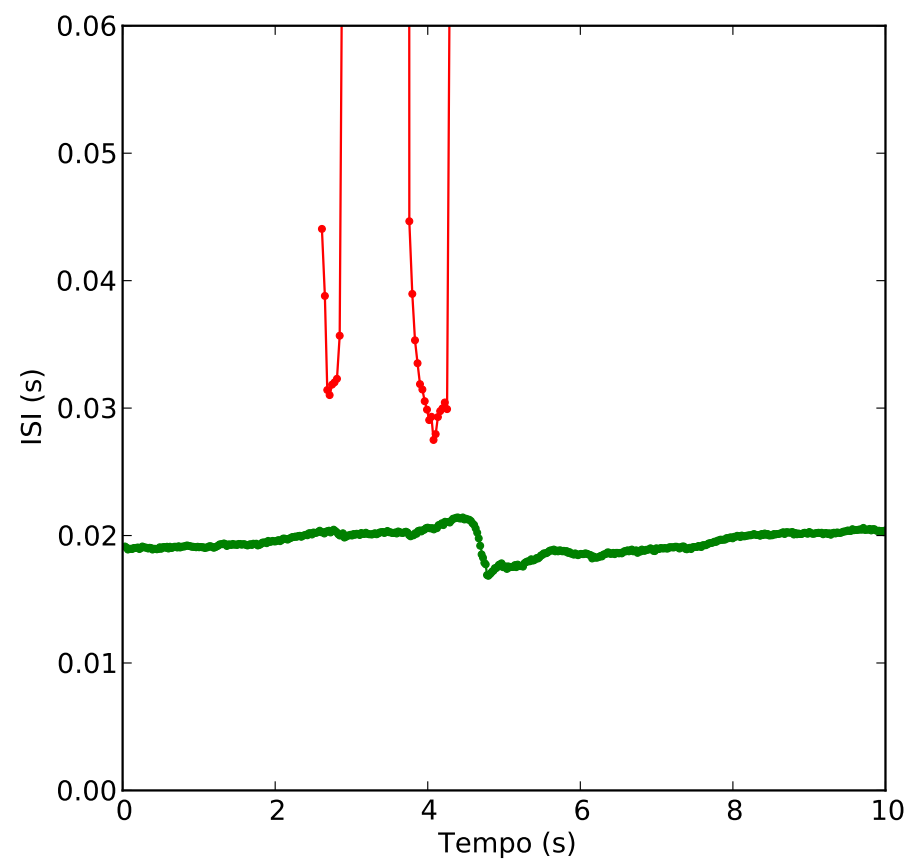

Figura 24 - Intervalos entre descargas em experimento com dois peixes, usando assinatura DTCWPT. 
Neste caso, o método com DT-CWPT foi mais preciso, aparentemente não apresentando nenhum erro de deteção no trecho de sinal apresentado. O erro no método com FFT foi devido à classificação indevida de uma descarga de amplitude muito baixa $(0,5$ V) em um único canal da aquisição. Apesar de ser extremamente raro observar erros em descargas com amplitude acima de 0,5 V, pode ser necessário ao experimentador ajustar o limiar do discriminador ou tentar reduzir o nível de ruído no circuito nesses casos.

Foi realizada aquisição de um total de 45 minutos, depois de os peixes estarem juntos no aquário ao longo de cerca de uma hora. Durante toda a aquisição, o peixe representado na cor vermelha disparou apenas eventualmente, totalizando cerca de $1 \%$ do total de disparos. Todos os trechos de disparo foram curtos, como o representado na figura. Este peixe foi o mesmo utilizado no experimento da Figura 21. 


\section{Conclusões}

Desenvolvemos e implementamos um método para identificar o peixe de origem de descargas do órgão elétrico emitidas durante uma aquisição com dois peixes em um mesmo aquário. O método foi validado, e sua precisão foi estimada em $96 \%$, que é um bom resultado, considerando que nossa meta inicial era de 95\%. Não temos conhecimento de nenhum outro método que permita realizar este tipo de experimento. Desta forma, este trabalho abre novas perspectivas para o estudo da eletrocomunicação em peixes da espécie Gymnotus carapo.

Trabalhos futuros poderão melhorar ainda mais a precisão do método, desenvolvendo técnicas de pós-processamento para detectar com maior precisão descargas efetuadas de forma simultânea pelos dois peixes. No entanto, o método, como está, já poderá ser utilizado em pesquisas da área. 


\section{REFERÊNCIAS}

1 BULLOCK, T. H.; FERNANDES-SOUZA, N.; GRAF, W.; HEILIGENBERG, W.; LANGNER, G.; MEYER, D.; PIMENTEL-SOUZA, F.; SCHEICH, H.; VIANCOUR, T. A. Aspectos do uso da descarga do órgão elétrico e eletrorrecepção nos Gymnotoidei e outros peixes amazônicos. Acta Amazonica, v. 9, n. 3, p. 549-572, 1979 .

2 KAWASAKI, M. Comparative analysis of the jamming avoidance response in African and South American wave-type electric fishes. Biological Bulletin, v. 191, n. 1, p. 103-108, 1996. doi 10.2307/1543070.

3 BENNETT, M. V.; GRUNDFEST, H. Electrophysiology of electric organ in Gymnotus carapo. The Journal of General Physiology, v. 42, n. 5, p. 1067-1104, 1959. doi 10.1085/jgp.42.5.1067.

4 CAPUTI, A.; BUDELLI, R. The electric image in weakly electric fish: I. A databased model of waveform generation in Gymnotus carapo. Journal of Computational Neuroscience, v. 2, n. 2, p. 131-147, 1995. doi 10.1007/BF00961884.

5 CASTEllo, M. E.; AGUilerA, P. A.; TRUJillo-CENOZ, O.; CAPUTI, A. A. Electroreception in Gymnotus carapo: pre-receptor processing and the distribution of electroreceptor types. Journal of Experimental Biology, v. 203, n. 21, p. 3279-3287, 2000 .

6 STOPA, R. M.; HOSHINO, K. Electrolocation-communication discharges of the fish Gymnotus carapo L. (Gymnotidae: Gymnotiformes) during behavioral sleep. Brazilian Journal of Medical and Biological Research, v. 32, n. 10, p. 1223-1228, 1999. doi 10.1590/S0100-879X1999001000008.

7 CAPURRO, A.; MALTA, C. P. Noise autocorrelation and jamming avoidance performance in pulse type electric fish. Bulletin of Mathematical Biology, v. 66, n. 4, p. 885-905, 2004. doi 10.1016/j.bulm.2004.02.002.

8 FORLIM, C. G. Estudo experimental da eletrocomunicação em peixes de campo elétrico fraco da espécie Gymnotus carapo - uma aplicação da teoria da informação. 2008. 44 p. Dissertação (Mestrado) — Instituto de Física, Universidade de São Paulo, São Paulo, 2008.

9 MCGREGOR, P. K.; WESTBY, G. M. Discrimination of individually characteristic electric organ discharges by a weakly electric fish. Animal Behaviour, v. 43, n. 6, p. 977-986, 1992. ISSN 0003-3472. doi 10.1016/S0003-3472(06)80011-4. 
10 HOPKINS, C. D. Temporal structure of non-propagated electric communication signals. Brain, Behavior and Evolution, v. 28, n. 1-3, p. 43-59, 1986. doi 10.1159/000118691.

11 BAYRAM, I.; SELESNICK, I. On the dual-tree complex wavelet packet and mband transforms. IEEE Transactions on Signal Processing, v. 56, n. 6, p. 2298-2310, 2008. ISSN 1053-587X. doi 10.1109/TSP.2007.916129.

12 WEICKERT, T.; BENJAMINSEN, C.; KIENCKE, U. Analytic wavelet packets - combining the dual-tree approach with wavelet packets for signal analysis and filtering. IEEE Transactions on Signal Processing, v. 57, n. 2, p. 493-502, 2009. ISSN 1053-587X. doi 10.1109/TSP.2008.2007922.

13 CORTES, C.; VAPNIK, V. Support-vector networks. Machine Learning, Springer Netherlands, v. 20, n. 3, p. 273-297, 1995. ISSN 0885-6125. doi 10.1007/BF00994018.

14 HEARST, M.; DUMAIS, S.; OSMAN, E.; PLATT, J.; SCHOLKOPF, B. Support vector machines. Intelligent Systems and their Applications, IEEE, v. 13, n. 4, p. 18 -28, 1998. ISSN 1094-7167. doi 10.1109/5254.708428.

15 HARRIS, F. J. On the use of windows for harmonic analysis with the discrete Fourier transform. Proceedings of the IEEE, v. 66, n. 1, p. 51-83, 1978. doi 10.1109/PROC.1978.10837.

16 CAPUTI, A. A. The electric organ discharge of pulse gymnotiforms: the transformation of a simple impulse into a complex spatio-temporal electromotor pattern. Journal of Experimental Biology, v. 202, n. 10, p. 1229-1241, 1999.

17 SELESNICK, I. W.; BARANIUK, R. G.; KINGSBURY, N. C. The dual-tree complex wavelet transform. IEEE Signal Processing Magazine, v. 22, n. 6, p. 123151, 2005. doi 10.1109/MSP.2005.1550194.

18 COIFMAN, R.; WICKERHAUSER, M. Entropy-based algorithms for best basis selection. IEEE Transactions on Information Theory, v. 38, n. 2, p. 713-718, 1992. ISSN 0018-9448. doi 10.1109/18.119732.

19 SHANnON, C. E. A mathematical theory of communication. Bell Systems Technical Journal, v. 27, p. 379-423, 623-656, 1948.

20 MEYER, D.; LEISCH, F.; HORNIK, K. The support vector machine under test. Neurocomputing, v. 55, n. 1-2, p. 169 - 186, 2003. ISSN 0925-2312. doi 10.1016/S09252312(03)00431-4. 
21 CHANG, C.-C.; LIN, C.-J. LIBSVM: a library for support vector machines. [S.l.], 2001. Disponível em: <http://www.csie.ntu.edu.tw/ cjlin/libsvm>. Acesso em: 12 jan. 2011.

22 FAN, R.-E.; CHEN, P.-H.; LIN, C.-J. Working set selection using second order information for training support vector machines. Journal of Machine Learning Research, v. 6, p. 1889-1918, 2005. ISSN 1532-4435.

23 KEERTHI, S. S.; LIN, C. J. Asymptotic behaviors of support vector machines with Gaussian kernel. Neural Computation, MIT Press, Cambridge, MA, USA, v. 15, n. 7, p. 1667-1689, 2003. ISSN 0899-7667. doi 10.1162/089976603321891855.

24 CHEN, P.-H.; FAN, R.-E.; LIN, C.-J. A study on SMO-type decomposition methods for support vector machines. IEEE Transactions on Neural Networks, v. 17, n. 4 , p. 893 - 908, 2006. ISSN 1045-9227. doi 10.1109/TNN.2006.875973.

25 FRIGO, M.; JOHNSON, S. FFTW: an adaptive software architecture for the FFT. In: IEEE INTERNATIONAL CONFERENCE ON ACOUSTICS, SPEECH AND SIGNAL PROCESSING, 1998. Proceedings... Seattle: IEEE, 1998. v. 3, p. 1381-1384. doi 10.1109/ICASSP.1998.681704. 